ARTICLE

\title{
Boosting oxygen reduction activity and enhancing stability through structural transformation of layered lithium manganese oxide
}

Xuepeng Zhong ${ }^{1}$, M'hamed Oubla $^{1}$, Xiao Wang${ }^{2}$, Yangyang Huang${ }^{1}$, Huiyan Zeng${ }^{1}$, Shaofei Wang ${ }^{3}$, Kun Liu 4 , Jian Zhou (1) ${ }^{4}$, Lunhua He ${ }^{5,6,7}$, Haihong Zhong ${ }^{8}$, Nicolas Alonso-Vante ${ }^{8}{ }^{8}$, Chin-Wei Wang (1) ${ }^{9}$, Wen-Bin Wu' Hong-Ji Lin ${ }^{9}$, Chien-Te Chen ${ }^{9}$, Zhiwei Hu (i) ${ }^{2 凶}$, Yunhui Huang ${ }^{1 凶} \&$ Jiwei Ma(i) ${ }^{1 凶}$

Structural degradation in manganese oxides leads to unstable electrocatalytic activity during long-term cycles. Herein, we overcome this obstacle by using proton exchange on welldefined layered $\mathrm{Li}_{2} \mathrm{MnO}_{3}$ with an O3-type structure to construct protonated $\mathrm{Li}_{2-x} \mathrm{H}_{x} \mathrm{MnO}_{3-n}$ with a P3-type structure. The protonated catalyst exhibits high oxygen reduction reaction activity and excellent stability compared to previously reported cost-effective Mn-based oxides. Configuration interaction and density functional theory calculations indicate that $\mathrm{Li}_{2-\mathrm{x}} \mathrm{H}_{\mathrm{x}} \mathrm{MnO}_{3-\mathrm{n}}$ has fewer unstable $\mathrm{O} 2 \mathrm{p}$ holes with a $\mathrm{Mn}^{3.7+}$ valence state and a reduced interlayer distance, originating from the replacement of $\mathrm{Li}$ by $\mathrm{H}$. The former is responsible for the structural stability, while the latter is responsible for the high transport property favorable for boosting activity. The optimization of both charge states to reduce unstable $\mathrm{O} 2 \mathrm{p}$ holes and crystalline structure to reduce the reaction pathway is an effective strategy for the rational design of electrocatalysts, with a likely extension to a broad variety of layered alkalicontaining metal oxides.

\footnotetext{
${ }^{1}$ Shanghai Key Laboratory for R\&D and Application of Metallic Functional Materials, Institute of New Energy for Vehicles, School of Materials Science and Engineering, Tongji University, Shanghai, China. ${ }^{2}$ Max Planck Institute for Chemical Physics of Solids, Dresden, Germany. ${ }^{3}$ Australian Centre for Neutron Scattering, Australian Nuclear Science and Technology Organization, Kirrawee DC, NSW, Australia. ${ }^{4}$ Center for Alloy Innovation and Design, State Key Laboratory for Mechanical Behavior of Materials, Xi'an Jiaotong University, Xi'an, China. ${ }^{5}$ Beijing National Laboratory for Condensed Matter Physics, Institute of Physics, Chinese Academy of Sciences, Beijing, China. ${ }^{6}$ Songshan Lake Materials Laboratory, Dongguan, China. ${ }^{7}$ Spallation Neutron Source Science Center, Dongguan, China. ${ }^{8}$ IC2MP, UMR-CNRS 7285, University of Poitiers, Poitiers, France. ${ }^{9}$ National Synchrotron Radiation Research Center,

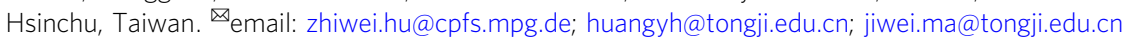


T he oxygen reduction reaction (ORR) plays an important role in energy conversion, spanning from polymer membrane fuel cells to metal-air batteries ${ }^{1}$. Sluggish ORR kinetics can be efficiently activated using platinum-based electrocatalysts. The cost and scarcity of platinum, however, have limited its practical applications. As a result, non-noble metal group electrocatalysts have received increasing attention for their practical application in energy conversion systems ${ }^{2-4}$. Manganese-based oxides have captured much attention because of their natural abundance, low cost, and nontoxicity ${ }^{5}$. Among them, $\mathrm{MnO}_{2}$ has been reported as a promising catalyst for the ORR in alkaline medium ${ }^{6-12}$, including various polymorphs. Its basic structural unit is a $\left[\mathrm{MnO}_{6}\right]$ octahedron. The $\left[\mathrm{MnO}_{6}\right]$ unit with corner- and edge-sharing forms $\mathrm{MnO}_{2}$, whose structure can be divided into three categories: one-dimensional (1D) tunneled structure $\left(\alpha-, \beta-\right.$, and $\gamma-\mathrm{MnO}_{2}$ ), two-dimensional (2D) layered structure $\left(\delta-\mathrm{MnO}_{2}\right)$, and three-dimensional (3D) structure $(\lambda$ $\mathrm{MnO}_{2}$ ). Based on previous reports ${ }^{9}, 13$, electrochemical performance of $\mathrm{MnO}_{2}$ depends strongly on the crystal structure and chemical composition. Among the different crystal structures of $\mathrm{MnO}_{2}, \delta-\mathrm{MnO}_{2}$ is promising because its unique layered structure can provide a highly efficient transport pathway for the ORR ${ }^{14-16}$ and has a relatively high Brunauer-Emmett-Teller (BET) surface area. Nevertheless, layered manganese oxide forms a metastable structure during the electrocatalytic reaction due to the loss of active manganese ions arising from the disproportionation reaction. Its practical application is limited by these instabilities. The results of previous studies ${ }^{17-20}$ show that tuning the $\mathrm{O} 2 p$ hole concentration, induced by the structural regulation of layered manganese oxide, can be considered an effective strategy to overcome this challenge. In the case of $\mathrm{Co}^{4+}$ oxide (e.g., $\mathrm{SrCoO}_{3}$ ), earlier studies specify that only $8 \%$ of the $3 d^{3}$ equivalent to $\mathrm{Co}^{3.4+}$, usually described as $\mathrm{SrCoO}_{3-\mathrm{d}}$, shows stable oxygen evolution activity ${ }^{18-20}$. In addition, shortening the reaction path within metal oxides helps to unlock the transport property, thus boosting the catalytic activity promoting hydrogen evolution ${ }^{21}$.

Motivated by the abovementioned guidelines concerning the production of fewer unstable $\mathrm{O} 2 p$ holes to stabilize the structure, the short interlayer distance can be considered responsible for adjusting the ORR activity within layered manganese oxides. As a proof of concept, we investigated a well-defined layered model system $\mathrm{Li}_{2} \mathrm{MnO}_{3}$ (written in layer notation as $\mathrm{Li}\left[\mathrm{Li}_{0.33} \mathrm{Mn}_{0.67}\right] \mathrm{O}_{2}$ ) because of its instability against oxygen release ${ }^{22,23}$ and its strong hydrogen bonding ${ }^{24}$ through proton exchange $\left(\mathrm{H}_{\mathrm{x}} \mathrm{Li}_{1-\mathrm{x}}\left[\mathrm{H}_{\mathrm{y}} \mathrm{Li}_{0.33-}\right.\right.$ $\left.{ }_{\mathrm{y}} \mathrm{Mn}_{0.67}\right] \mathrm{O}_{2-\mathrm{n}}$, denoted as HLM), which allowed us to effectively tune the $\mathrm{O} 2 p$ hole concentration and the interlayer distance, making the perfect venue to validate our concept. In this work, we demonstrated that the structural transition induced by proton exchange leads to decreases in unstable $\mathrm{O} 2 p$ holes and the interlayer distance, thereby enhancing structural stability and boosting oxygen reduction activity. This HLM catalyst exhibits excellent stability over 10,000 cycles, which is much superior to that of other reported manganese-based oxides and even comparable to that of the $\mathrm{Mn}$ single-atom catalyst ${ }^{25}$, 26. Moreover, HLM shows a high ORR activity with a larger limiting current density of $-5.46 \mathrm{~mA} \mathrm{~cm}^{-2}$ at $1600 \mathrm{rpm}$ and a higher specific activity than other reported manganese-based oxides. In addition, the half-wave potential is only ca. $60 \mathrm{mV}$ less than the benchmark catalyst $\mathrm{Pt} / \mathrm{C}$. The practical application of HLM is demonstrated in a membrane-less micro laminar flow fuel cell configuration. This work highlights the beneficial use of proton exchange, which enables unlocking the activity and stability of layered alkalicontaining metal oxides for the ORR, offering a paradigm for the rational design of electrocatalytic oxides for energy conversion technology.

\section{Results}

Structure transformation induced by proton exchange. The well-defined layered $\mathrm{O} 3$-type $\mathrm{Li}_{2} \mathrm{MnO}_{3}$ served as the soft template to build a P3-type HLM. Acid leaching was deployed to exchange lithium from thermodynamically stable $\mathrm{Li}_{2} \mathrm{MnO}_{3}$ and form HLM. The delithiation process was accompanied by a sharing of closepacked oxygen planes (Figs. 1a, b), resulting in a change from an $\mathrm{O} 3$ stacking sequence $(\mathrm{ABC})$ to a $\mathrm{P} 3$ stacking sequence (AABBCC). The crystal structure was characterized by $\mathrm{X}$-ray diffraction (XRD) analysis, which revealed the phase change upon acid leaching, identified by new peaks located at $\sim 38^{\circ}$ and $\sim 49^{\circ}$

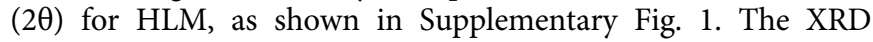
pattern of HLM nearly matches the $\mathrm{HCrO}_{2}$ structure in the $R-3 m$ group. Hydrogen is located in trigonal prismatic sites within the $\mathrm{HCrO}_{2}$ structure, yielding strong hydrogen bonding. The broad peak located at $2700-3050 \mathrm{~cm}^{-1}$ in the Fourier transform infrared (FTIR) spectra indicates the presence of strong H-bonded $-\mathrm{OH}$ groups in the P3 structure (Supplementary Fig. 2). Strong hydrogen bonding can be further considered a driving force for the layer stacking change from O3- to P3-type structures, making the structure more stable ${ }^{22}$. The (001) peak of HLM shifts towards a higher $2 \theta$ compared to $\mathrm{Li}_{2} \mathrm{MnO}_{3}$, revealing that the interlayer spacing decreases upon the replacement of $\mathrm{Li}$ by $\mathrm{H}$, as discussed below. The conservation of the peak located at $\sim 21^{\circ}$ $(2 \theta)$ after acid leaching suggests cation ordering in the TM layers, leading to a decrease in symmetry from $R-3 m$ to $C 2 / m^{22}, 24$. However, the smoothness of this peak after the delithiation process suggests cation deficiency within the TM layer ${ }^{27}$.

Due to the weak X-ray scattering ability of $\mathrm{Li}$ and $\mathrm{H}$, neutron diffraction (ND) was employed to investigate the long-range structure of the $\mathrm{Li}_{2} \mathrm{MnO}_{3}$ and as-prepared HLM samples. As expected, joint Rietveld refinements of $\mathrm{Li}_{2} \mathrm{MnO}_{3}$ and HLM using XRD and ND data, shown in Fig. 1c, d and Table 1, confirmed the monoclinic structure with $C 2 / m$ symmetry. The refined lattice parameters were $a=4.918(5) \AA, b=8.487$ (9) $\AA, c=4.945(7) \AA$, and $V=195.3(9) \AA^{3}$ for $\mathrm{Li}_{2} \mathrm{MnO}_{3}$ and $a=5.016(1) \AA, b=8.622$ (5) $\AA, c=4.858(5) \AA$, and $V=200.2(9) \AA^{3}$ for HLM. Similar to previous reports 24,28 , a decrease in the $c$ parameter was observed after acid leaching, while an increase in both $a$ and $b$ could be assigned to proton exchange in HLM. The bond distance was calculated from the refined atom position, and the shortest $\mathrm{O}-\mathrm{O}$ distances between TM layers were decreased from $\sim 3.0 \AA$ $\left(\mathrm{Li}_{2} \mathrm{MnO}_{3}\right)$ to $\sim 2.5 \AA$ (HLM), as shown in Supplementary Fig. 3 . This was consistent with the strong hydrogen bonding distance ${ }^{24}$. Furthermore, the refined data suggest the complete extraction of $\mathrm{Li}$ within the $\mathrm{Li}$ interlayer $(\mathrm{Li}(2 \mathrm{c})$ and $\mathrm{Li}(4 \mathrm{~h}))$ and partial removal from the TM layer $(\operatorname{Li}(2 b))$. The chemical formula of HLM determined from the refined occupancies was $\mathrm{H}_{1.0}\left[\mathrm{H}_{0.13} \mathrm{Li}_{0.17} \square \square_{0.03} \mathrm{Mn}_{0.67}\right] \mathrm{O}_{1.89} \square_{0.11}$ ( $\square$ represents vacancies; Supplementary Table 1), yielding a Li/Mn ratio of $\sim 0.254$ and an average oxidation state of $\mathrm{Mn}^{3.7+}$ arising from oxygen release from the lattice ${ }^{29-31}$. The $\mathrm{Li} / \mathrm{Mn}$ ratio was also determined by inductively coupled plasma-optical emission spectrometry (ICPOES) to be $\sim 0.25$, which was consistent with the refined chemical composition. The thermogravimetric analysis (TGA) profile of HLM is shown in Supplementary Fig. 4. The calculated weight loss was $\sim 15 \%$ due to the departure of -OH groups between 100 and $350{ }^{\circ} \mathrm{C}$, which was close to the experimental loss of $\sim 12 \%$, confirming that the content of $\mathrm{H}$ within HLM was close to the refined chemical formula.

Figure 1e, f shows nanometric particles of the as-prepared HLM, unlike the large platelets of the precursor $\mathrm{Li}_{2} \mathrm{MnO}_{3}$ (Supplementary Fig. 5). The decrease in particle size was due to the "chemical grinding effect" induced by acid leaching. This was consistent with the increase in the BET surface area from $\sim 34 \mathrm{~m}^{2}$ 

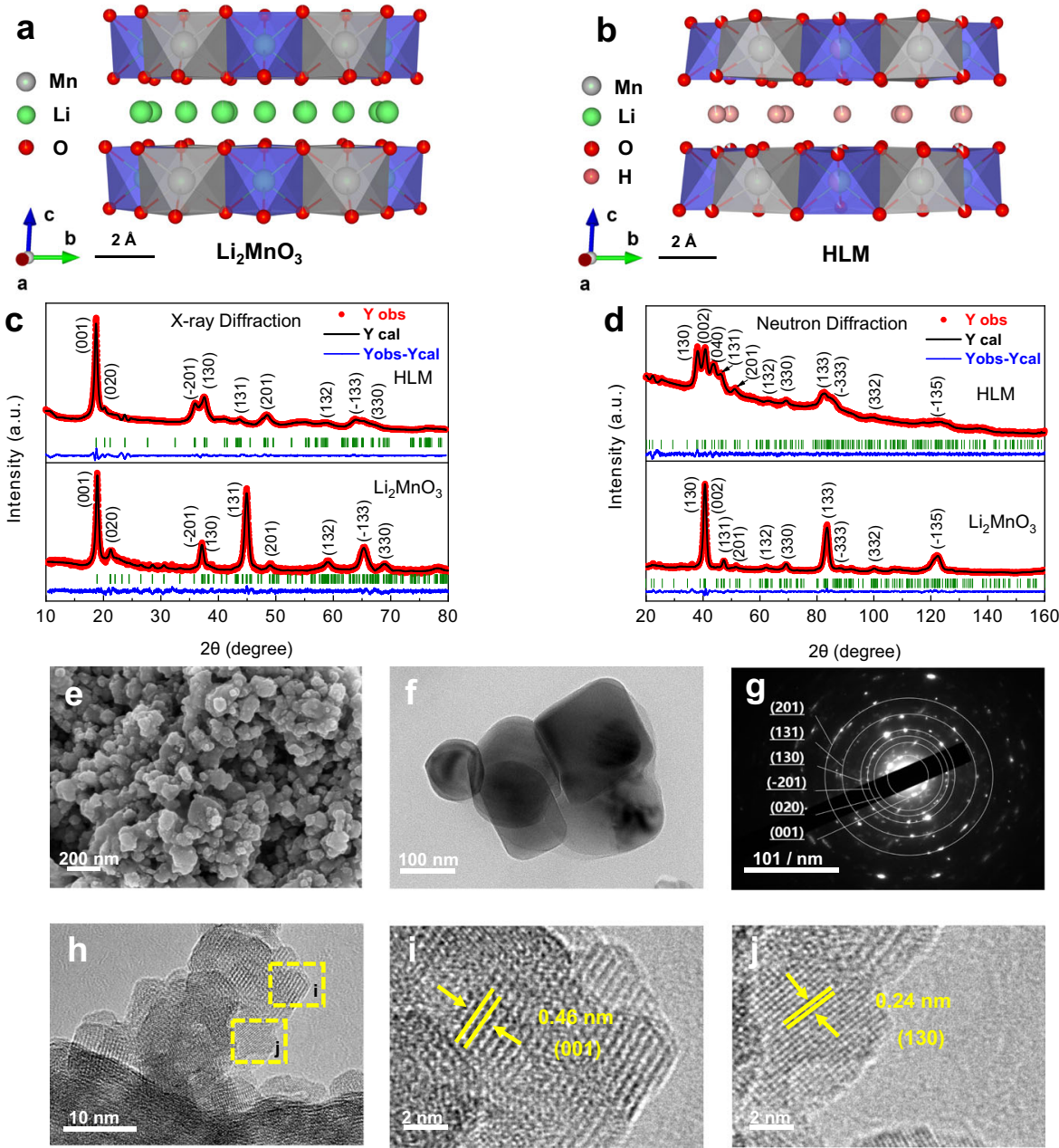

Fig. 1 Structural characterization of $\mathrm{Li}_{\mathbf{2}} \mathbf{M n O}_{\mathbf{3}}$ and $\mathbf{H L M}$. a Crystal structure configurations of $\mathrm{Li}_{2} \mathrm{MnO}_{3}$ (O3 stacking) and $\mathbf{b} \mathrm{HLM}$ (P3 stacking). Rietveld refinement profiles using $\mathbf{c}$ X-ray diffraction and $\mathbf{d}$ neutron diffraction data for pristine $\mathrm{Li}_{2} \mathrm{MnO}_{3}$ (Crystallography Open Database ID: 1008373) and asprepared HLM (Crystallography Open Database ID: 4001282) samples. The red circles illustrate the observed pattern, the black solid line is the calculated pattern, the green vertical markers show the calculated Bragg reflection positions, and the blue line is the difference between the observed pattern and the calculated pattern. e SEM image of HLM. f TEM images of HLM. $\mathbf{g}$ Electron diffraction patterns from [101] of HLM. h HR-TEM images of HLM. i, $\mathbf{j}$ HR-TEM images of selected regions of HLM.

\begin{tabular}{|c|c|c|c|c|c|c|}
\hline Atom & Wyckoff site & $x / a$ & $y / b$ & $z / c$ & $B_{\text {iso }}$ & Occup. \\
\hline \multicolumn{7}{|c|}{$\begin{array}{l}\left.\mathrm{Li}_{2} \mathrm{MnO}_{3} \text { (space group: } \mathrm{C} 2 / m\right), Z=4 a=4.918(5) \AA, b=8.487(9) \AA, c=4.945(7) \AA, \beta=108.8(5)^{\circ}, V=195.3(9) \AA^{3} \chi^{2}=1.61, R_{\mathrm{F}}=1.36 \%, R_{\mathrm{B}}=2.59 \% \text {, } \\
R_{\mathrm{p}}=18.7 \%, R_{\mathrm{wp}}=17.7 \%\end{array}$} \\
\hline $\mathrm{Mn}$ & $4 \mathrm{~g}$ & 0 & $0.1688(9)$ & 0 & $1.681(4)$ & $1.000(5)$ \\
\hline Li & $2 b$ & 0 & 0.5 & 0 & $2.471(6)$ & $1.000(5)$ \\
\hline $\mathrm{Li}$ & $2 c$ & 0 & 0 & 0.5 & $1.318(6)$ & $0.999(8)$ \\
\hline $\mathrm{Li}$ & $4 \mathrm{~h}$ & 0 & $0.6675(2)$ & 0.5 & $0.588(4)$ & $0.992(7)$ \\
\hline o & $4 i$ & $0.2286(5)$ & 0 & $0.2393(1)$ & $0.144(9)$ & $1.000(8)$ \\
\hline O & $8 \mathrm{j}$ & $0.2308(5)$ & $0.3437(7)$ & $0.2384(4)$ & 0.691 (9) & $0.999(7)$ \\
\hline \multicolumn{7}{|c|}{$\begin{array}{l}\text { HLM (space group: } C 2 / m), Z=6 a=5.016(1) \AA, b=8.622(5) \AA, c=4.858(5) \AA, \beta=107.7(4)^{\circ}, V=200.2(9) \AA^{3} \chi^{2}=1.5, R_{\mathrm{F}}=2.1 \%, R_{\mathrm{B}}=4.3 \%, R_{\mathrm{p}}= \\
19.1 \%, R_{\mathrm{wp}}=17.4 \%\end{array}$} \\
\hline $\mathrm{Mn}$ & $4 \mathrm{~g}$ & 0 & $0.1746(5)$ & 0 & $2.809(4)$ & $1.000(6)$ \\
\hline Li & $2 b$ & 0 & 0.5 & 0 & $1.280(6)$ & $0.516(8)$ \\
\hline $\mathrm{H}$ & $2 b$ & 0 & 0.5 & 0 & $7.340(8)$ & $0.379(5)$ \\
\hline $\mathrm{H}$ & $2 c$ & 0 & 0 & 0.5 & $1.089(6)$ & $0.960(5)$ \\
\hline $\mathrm{H}$ & $4 \mathrm{~h}$ & 0 & $0.7581(7)$ & 0.5 & $1.5(6)$ & $0.990(5)$ \\
\hline O & $4 i$ & $0.1171(8)$ & 0 & $-0.2111(8)$ & $1.679(8)$ & $0.876(5)$ \\
\hline O & $8 \mathrm{j}$ & $0.1389(6)$ & $0.3370(8)$ & $-0.2337(6)$ & $2.115(9)$ & $0.980(3)$ \\
\hline
\end{tabular}



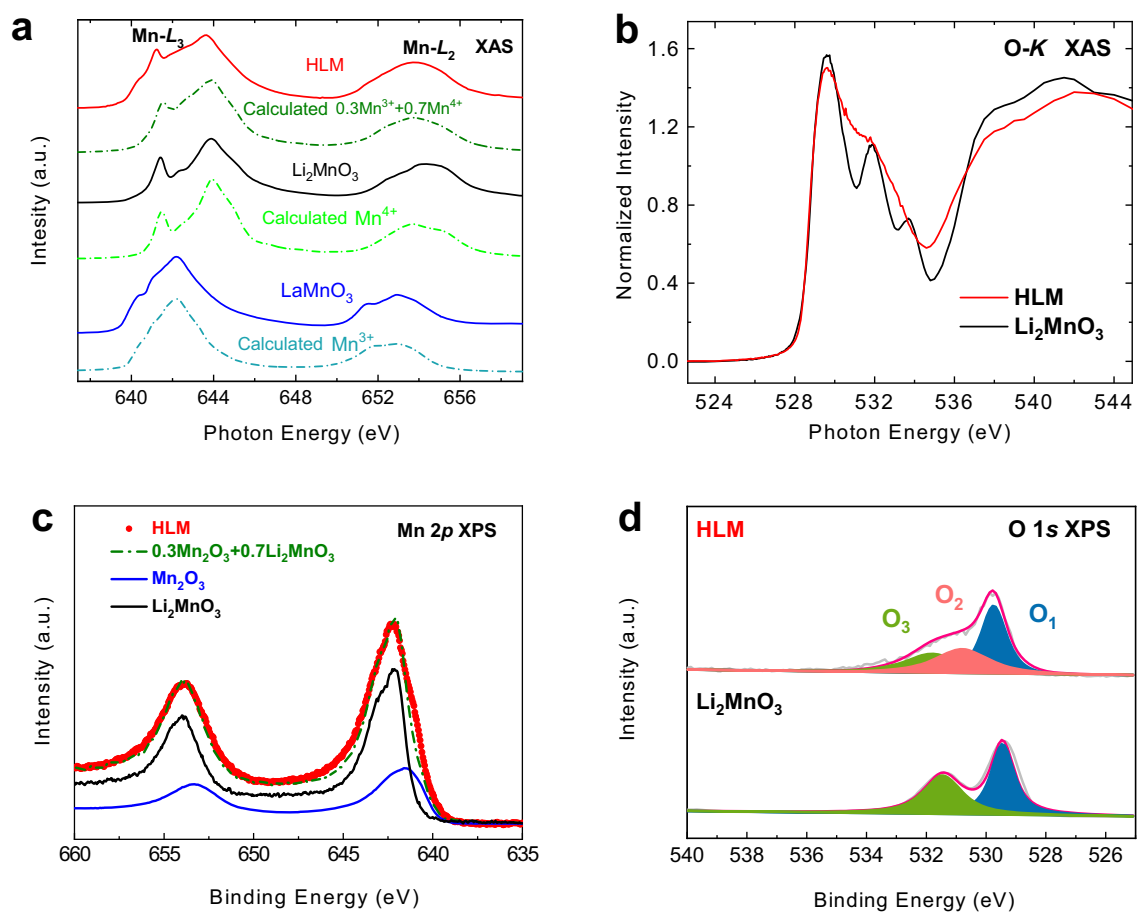

Fig. 2 Electronic structure characterization by XAS and XPS. a Mn- $L_{2,3} X A S$ spectra of $\mathrm{HLM}$ (red) together with $\mathrm{Li}_{2} \mathrm{MnO}_{3}$ (black) and $\mathrm{LaMnO}_{3}{ }^{35}$ (blue) as $\mathrm{Mn}^{4+}$ and $\mathrm{Mn}^{3+}$ references. The dashed lines below the experimental data are the corresponding calculated spectra. b O-K XAS spectra of HLM (red) and $\mathrm{Li}_{2} \mathrm{MnO}_{3}$ (black). c High-resolution Mn 2p XPS spectra of HLM (red) and sum (olive) of $\mathrm{Mn}_{2} \mathrm{O}_{3}$ (blue) and $\mathrm{Li}_{2} \mathrm{MnO}_{3}$ (black). d High-resolution O 1 s XPS spectra of the as-prepared $\mathrm{HLM}$ and pristine $\mathrm{Li}_{2} \mathrm{MnO}_{3}$ samples.

$\mathrm{g}^{-1}\left(\mathrm{Li}_{2} \mathrm{MnO}_{3}\right)$ to $\sim 117 \mathrm{~m}^{2} \mathrm{~g}^{-1}$ (HLM) (Supplementary Fig. 6). As a result, HLM possessed a larger surface area, which could potentially provide more active sites for electrocatalytic activity. The selected area electron diffraction (SAED) pattern of the HLM showed six different diffraction rings of (001), (020), (-201), (130), (131), and (201), as shown in Fig. 1g. Figure 1h shows a high-resolution transmission electron microscopy (HR-TEM) image for HLM, demonstrating high crystallinity with interplanar distances of $0.46 \mathrm{~nm}$ and $0.24 \mathrm{~nm}$ for the (001) and (130) planes, respectively (Fig. 1i, j). These results are in good agreement with the XRD pattern observations (Supplementary Fig. 7).

Electronic structures. The electronic structure was characterized by joint soft X-ray absorption spectroscopy (XAS) and X-ray photoelectron spectroscopy (XPS). The energy position and multiplet spectral feature of the XAS spectrum at the $3 d$ transition metal elements $L_{2,3}$ edges are highly sensitive to their valence state $^{32,33}$ and local environment ${ }^{34}$. Figure 2 a shows the $\mathrm{Mn}-L_{2,3}$ XAS spectra of HLM (red) together with $\mathrm{LaMnO}_{3}$ (blue from Burnus et al. ${ }^{35}$ ) and $\mathrm{Li}_{2} \mathrm{MnO}_{3}$ (black) as a $\mathrm{Mn}^{3+}$ reference and a $\mathrm{Mn}^{4+}$ reference, respectively. The energy position of the HLM spectrum is located between $\mathrm{LaMnO}_{3}$ and $\mathrm{Li}_{2} \mathrm{MnO}_{3}$, much closer to the latter, confirming the mixed-valence states of the $\mathrm{Mn}$ ion. Using the configuration interaction cluster model (discussed below), we can closely reproduce the $\mathrm{Mn}^{3+}$ oxide (dashed line below $\mathrm{LaMnO}_{3}$ ) and $\mathrm{Mn}^{4+}$ oxide (dashed line below $\mathrm{Li}_{2} \mathrm{MnO}_{3}$ ). In turn, the HLM contains $30 \% \mathrm{Mn}^{3+}$ and $70 \% \mathrm{Mn}^{4+}$ (dashed line below HLM), giving rise to an average oxidation state of $\mathrm{Mn}^{3.7+}$ in HLM. The calculations were performed using CTM4XAS $^{36,37}$. This theory incorporates a correct absolute weight of each Mn valence state, but the energy position of each valence state has to be adjusted according to experiments from the reference materials $32,35,38,39$. The spectral broadening of mixed $\mathrm{Mn}^{3+}$ and $\mathrm{Mn}^{4+}$ is due to a partial overlapping of $\mathrm{Mn}^{3+}$ and $\mathrm{Mn}^{4+}$. However, the sharp lower-energy peak $(641.6 \mathrm{eV})$ at the $\mathrm{Mn}-\mathrm{L3}$ edge of $\mathrm{Mn}^{4+}$ oxide is a sensitive fingerprint for the $\mathrm{Mn}^{4+}$ content. The difference between HLM and $\mathrm{Li}_{2} \mathrm{MnO}_{3}$ is most likely related to the removal of oxygen from the lattice upon the replacement of $\mathrm{Li}$ by less metallic $\mathrm{H}$ ions, which creates Jahn-Teller $\mathrm{Mn}^{3+}$ ions ${ }^{40}$. Figure $2 \mathrm{~b}$ presents the normalized $\mathrm{O} \mathrm{K}$ edge XAS spectra of $\mathrm{Li}_{2} \mathrm{MnO}_{3}$ and HLM. The pre-edge peaks below $533 \mathrm{eV}$ are the result of $\mathrm{O} 2 p$ state mixing with the $3 d$ transition element $3 d$ state. The spectral weights of lower-energy peaks increase with increasing valence state ${ }^{41}$. The lowest preedge peak is related to the $3 d$ state of the $\mathrm{Mn}^{4+}$ ion ${ }^{33}$. The loss of its spectral weight in the HLM sample with respect to that in $\mathrm{Li}_{2} \mathrm{MnO}_{3}$ again indicates a lower valence state in the former. A slight decrease in the $\mathrm{Mn}$ valence state reduces the unstable $\mathrm{O} 2 p$ holes close to the Fermi level and enhances the ORR stability ${ }^{17}$, as discussed below. Spectral broadening after the loss of oxygen can also be seen in the O-K XAS spectrum of HLM since the orbital character is smeared out. This indicates an increase in the transport property, which is responsible for enhancing the ORR activity of HLM. XPS was used to further characterize the change in the chemical state. Figure $2 c$ shows the Mn $2 p$ XPS spectra of $\mathrm{HLM}$ (red) and those of $\mathrm{Li}_{2} \mathrm{MnO}_{3}$ (black) and $\mathrm{Mn}_{2} \mathrm{O}_{3}$ (blue) as $\mathrm{Mn}^{4+}$ and $\mathrm{Mn}^{3+}$ references, respectively, which indicates that $\mathrm{Mn}$ exists in mixed-valence states in HLM. The ratio of $\mathrm{Mn}^{3}$ $+/ \mathrm{Mn}^{4+}$ determined by XPS is approximately 3:7, indicating an average oxidation state of $\mathrm{Mn}^{3.7+}$, which is in good agreement with $\mathrm{Mn}-L_{2,3}$ XAS and refined data from joint XRD and NPD analyses. The charge compensation for the loss of oxygen is represented by the decrease in the average valence state of manganese. As shown in Fig. 2d, the high-resolution $\mathrm{O} 1 s$ XPS spectrum of $\mathrm{Li}_{2} \mathrm{MnO}_{3}$ exists in $\mathrm{O} 1$ and $\mathrm{O} 3$ forms $(529.5 \mathrm{eV}$ and $531.2 \mathrm{eV}$, respectively), corresponding to the $\mathrm{O}^{2-}$ peak and the oxygenated deposited species or $\mathrm{CO}_{3}{ }^{2-}$, respectively. In contrast, the $\mathrm{O} 1 \mathrm{~s}$ signal of nonstoichiometric oxygen species (O2) for deficiencies centered at $\sim 531 \mathrm{eV}$ can be observed, further confirming the presence of oxygen vacancies within $\mathrm{HLM}^{42,43}$. 

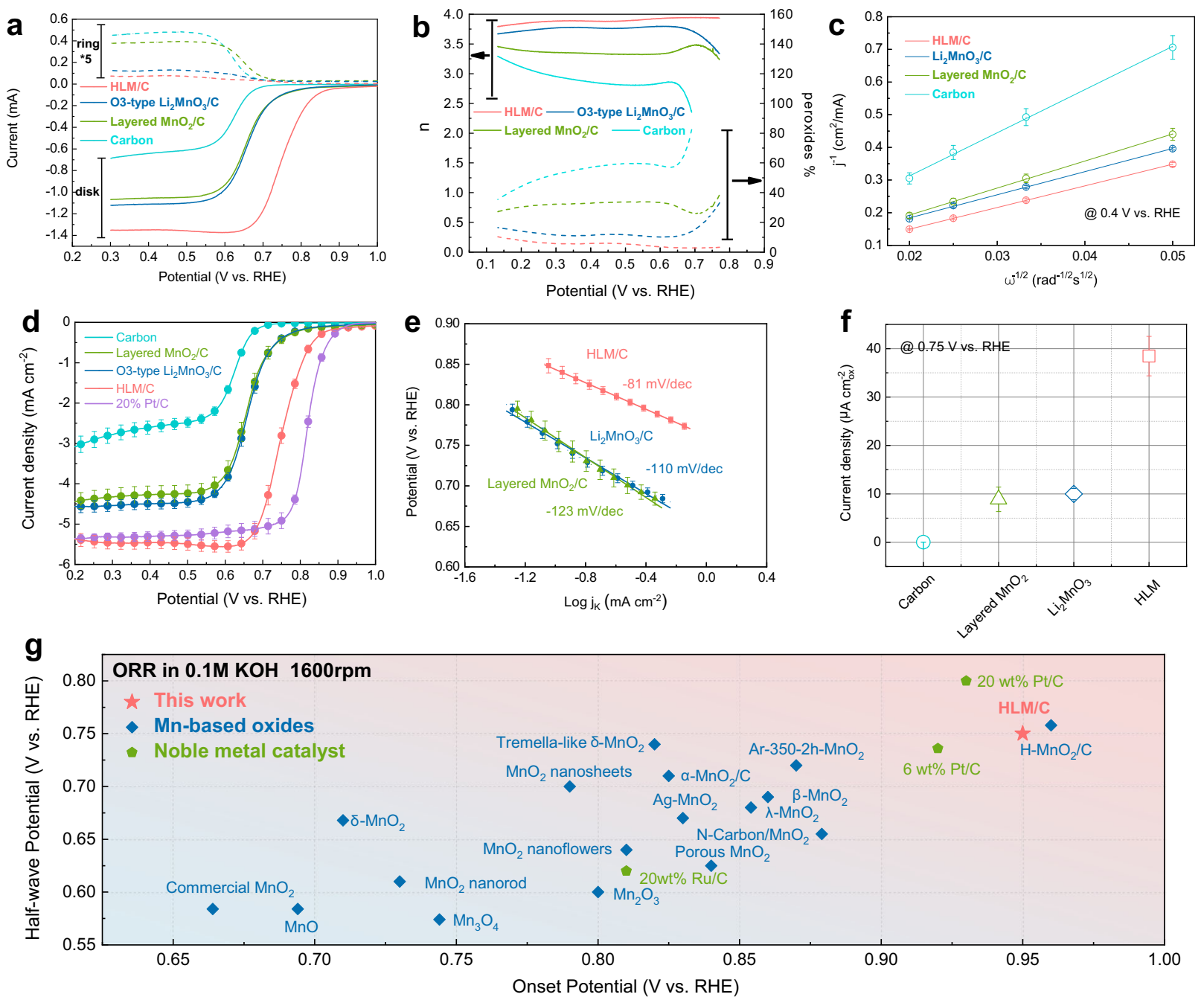

Fig. 3 Electrochemical activity of the obtained samples in $\mathbf{0 . 1} \mathbf{~ M ~} \mathbf{K O H}$ aqueous solution. a ORR polarization curves of $\mathrm{HLM}_{\mathrm{L}} \mathrm{C}, \mathrm{Li} 2 \mathrm{MnO} / \mathrm{C}$, and layered $\mathrm{MnO}_{2} / \mathrm{C}$ and carbon at a rotation rate of $1600 \mathrm{rpm}$ in $\mathrm{O}_{2}$-saturated $0.1 \mathrm{M} \mathrm{KOH}$ solution. b Electron transfer numbers $(n)$ and $\mathrm{HO}_{2}{ }^{-}$yields $(\mathrm{y})$ for $\mathrm{HLM} / \mathrm{C}$, $\mathrm{Li}_{2} \mathrm{MnO}_{3} / \mathrm{C}$, layered $\mathrm{MnO}_{2} / \mathrm{C}$ and carbon. $\mathbf{c}$ Koutecky-Levich plots. d Linear sweep voltammetry curves of $\mathrm{HLM} / \mathrm{C}, \mathrm{Li}_{2} \mathrm{MnO}_{3} / \mathrm{C}$, layered $\mathrm{MnO} 2 / \mathrm{C}$, carbon, and $20 \% \mathrm{Pt} / \mathrm{C}$ obtained at $\mathrm{O}_{2}$-saturated $0.1 \mathrm{M} \mathrm{KOH}$ with a scan rate of $5 \mathrm{mV} \mathrm{s}^{-1}$. e The Tafel plots of $\mathrm{HLM} / \mathrm{C}_{1} \mathrm{Li}_{2} \mathrm{MnO}_{3} / \mathrm{C}_{\text {and layered }} \mathrm{MnO}_{2} / \mathrm{C}$. f Specific activities of $\mathrm{HLM} / \mathrm{C}, \mathrm{Li}_{2} \mathrm{MnO}_{3} / \mathrm{C}$, layered $\mathrm{MnO}_{2} / \mathrm{C}$ and carbon. The current density at $0.75 \mathrm{~V}$ vs. RHE normalized by BET surface area is used as a benchmark for the comparison. $\mathbf{g}$ Comparison of HLM with other reported Mn-based oxides and noble metal catalysts. Note: (i) The onset potential is the potential at which the current density exceeds $0.1 \mathrm{~mA} \mathrm{~cm}^{-2}$, and the half-wave potential is the potential at which the current density is equal to half of the diffusion current density. (ii) The onset potential and half-wave potential were taken from the text or directly read from the graphics. (iii) The mass loading of reported Mn-based oxides ranges from $0.073 \mathrm{mg} \mathrm{cm}^{-2}$ to $0.465 \mathrm{mg} \mathrm{cm}^{-2}$. (iv) Error bars represent the standard deviation of at least three independent measurements.

Enhanced electrochemical activity. The electrochemical activity towards the ORR was evaluated in $0.1 \mathrm{M} \mathrm{KOH}$ solution. As shown in Fig. 3a, HLM/C exhibited a half-wave potential $\left(E_{1 / 2}\right)$ of $0.75 \mathrm{~V}$ vs. RHE, a smaller ring current and a larger disk current in all samples (the corresponding XRD pattern of layered $\mathrm{MnO}_{2}$ is shown in Supplementary Fig. 8). The electron transfer number $(n)$ and the $\mathrm{HO}_{2}^{-}$yield (y) were obtained from rotating ring-disk electrode (RRDE) measurements, as shown in Fig. 3b. Within the potential range of $0.1-0.8 \mathrm{~V}$ vs. RHE, for HLM/C, $\mathrm{n}$ was above 3.8 with $\mathrm{HO}_{2}{ }^{-}$yields below $\sim 10 \%$. This is a value comparable to that of the benchmark $\mathrm{Pt} / \mathrm{C}^{44}$. To further quantify the ORR pathway, the calculated electron transfer numbers $(n)$ of HLM/C, $\mathrm{Li}_{2} \mathrm{MnO}_{3} / \mathrm{C}$, layered $\mathrm{MnO}_{2} / \mathrm{C}$ and carbon at $0.4 \mathrm{~V}$ vs. RHE using Eqs. (1) and (2) were 3.99, 3.73, 3.19, and 2.00, respectively, approaching a 4-electron mechanism for the HLM/C sample, as shown in Fig. 3c. Koutecky-Levich (K-L) plots at different potential ranges of $0.2-0.5 \mathrm{~V}$ vs. RHE are shown in
Supplementary Fig. 9. Moreover, as shown in Fig. 3d, HLM/C yielded relatively high ORR activity, with a half-wave potential of only ca. $60 \mathrm{mV}$ less than $20 \mathrm{wt} \% \mathrm{Pt} / \mathrm{C}$.

The enhanced activity can be attributed to the reduced interlayer distance and the introduction of oxygen vacancies by ion exchange from $\mathrm{Li}$ to $\mathrm{H}$. The reduced interlayer spacing in the $c$ direction helps to reduce the electrochemical reaction pathway, while the oxygen vacancies acting as active adsorption sites can improve the interaction between the HLM surface and oxygencontaining species ${ }^{45}$. The Tafel plots were extracted from the mass transfer corrected LSV curves, as shown in Fig. 3e. The Tafel slope of HLM/C $\left(-81 \mathrm{mV} / \mathrm{dec}^{-1}\right)$ differs from that of $\mathrm{Li}_{2} \mathrm{MnO}_{3} / \mathrm{C}$ $\left(-110 \mathrm{mV} / \mathrm{dec}^{-1}\right)$ and layered $\mathrm{MnO}_{2} / \mathrm{C}\left(-123 \mathrm{mV} \mathrm{dec}^{-1}\right)$, suggesting that the ORR could be assigned to specific ratedetermining steps that depend on the coverage and surface chemistry. If the value of the Tafel slope is ca. $-60 \mathrm{mV} \mathrm{dec}^{-1}$, then the rate-determining step of the ORR is dominated by the 

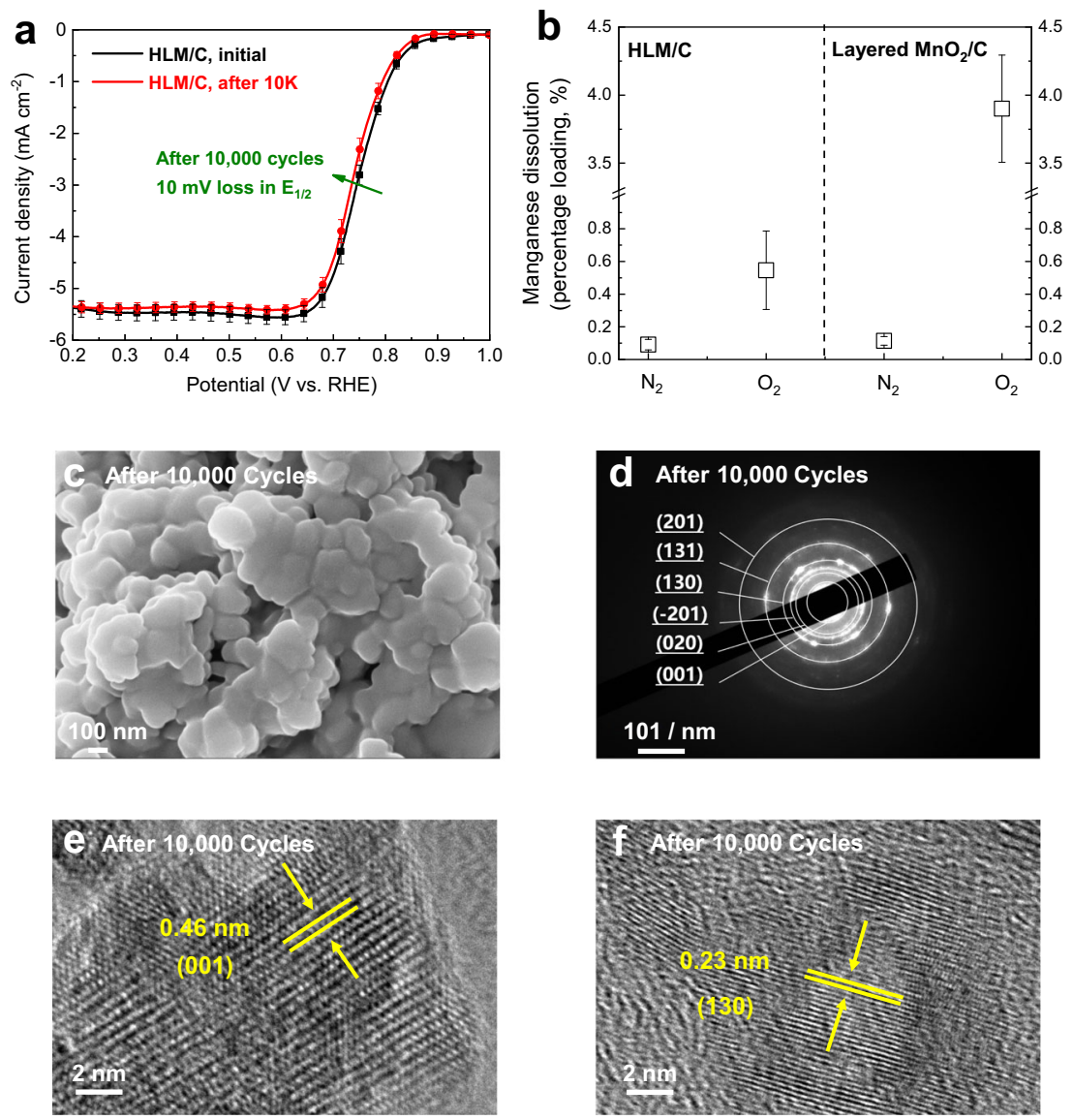

Fig. 4 Stability characterization and ion dissolution behaviors. a Stability studied by using potential cycling of HLM/C. b Total amount of Mn dissolution studied by ICP for HLM/C and layered $\mathrm{MnO}_{2} / \mathrm{C}$. Error bars represent the standard deviation of at least three independent measurements. $\mathbf{c}$ SEM image of HLM after 10,000 cycles. d SAED of HLM after 10,000 cycles. e, f Corresponding HR-TEM images with selected regions of HLM after 10,000 cycles.

ORR process after a one-electron transfer step. If the value of the Tafel slope is ca. $-120 \mathrm{mV} \mathrm{dec}^{-1}$, the single-electron transfer step is the rate-determining step ${ }^{46,47}$. Figure $3 \mathrm{f}$ shows the specific activities of $\mathrm{HLM} / \mathrm{C}, \mathrm{Li}_{2} \mathrm{MnO}_{3} / \mathrm{C}$, layered $\mathrm{MnO}_{2} / \mathrm{C}$, and carbon. The kinetic current density at $0.75 \mathrm{~V}$ vs. RHE normalized by BET surface area is used as a benchmark for the comparison ${ }^{48}$. HLM shows the highest current density, which is nearly four times higher than the current density of $\mathrm{Li}_{2} \mathrm{MnO}_{3}$. The charge transfer rate was measured by electrochemical impedance spectroscopy (EIS) in $\mathrm{O}_{2}$-saturated (sat.) $0.1 \mathrm{M}$ aqueous $\mathrm{KOH}$ solution. Among these catalysts, HLM/C exhibited the smallest charge transfer resistance $\left(R_{\mathrm{ct}} ;\right.$ Supplementary Fig. 10$) . R_{\mathrm{ct}}$ followed the sequence of $\mathrm{HLM} / \mathrm{C}<$ layered $\mathrm{MnO}_{2} / \mathrm{C}<\mathrm{Li}_{2} \mathrm{MnO}_{3} / \mathrm{C}$, confirming the enhanced transport property of the HLM/C catalyst. Notably, as shown in Fig. 3g, we compared HLM/C with other state-of-theart Mn-based oxides and noble metal catalysts in terms of halfwave potentials and onset potentials (Supplementary Table 2). HLM/C shows a high ORR activity, which outperforms most of the reported Mn-based oxides.

High stability. The electrochemical stability of HLM/C was examined by accelerated cyclic voltammetry over 10,000 cycles from $0.6 \mathrm{~V}$ to $1.0 \mathrm{~V}$ vs. RHE in $\mathrm{O}_{2}$-saturated $0.1 \mathrm{M} \mathrm{KOH}$. The catalyst was further subjected to the LSV test after 10,000 cycles, which showed excellent long-term stability (Fig. 4a), as evidenced by a $10 \mathrm{mV}$ loss of $E_{1 / 2}$ over 10,000 cycles, with a negligible decrease in the limiting current density over 10,000 cycles. The $\mathrm{HLM} / \mathrm{C}$ catalyst outperformed the $\mathrm{Li}_{2} \mathrm{MnO}_{3} / \mathrm{C}$, layered $\mathrm{MnO}_{2} / \mathrm{C}$ and $\mathrm{Pt} / \mathrm{C}$ (20 wt\% Pt/C, Johnson-Matthey) catalysts (Supplementary Fig. 11). A higher $\mathrm{E}_{1 / 2}$ loss was observed for $\mathrm{Li}_{2} \mathrm{MnO}_{3} / \mathrm{C}$ during repeated CV cycles. This loss was $24 \mathrm{mV}$ after 10,000 cycles, and was concomitant with a slight decrease in the limiting current density. From the point of view of the electronic structure, the P3-type HLM catalyst has fewer unstable $\mathrm{O} 2 p$ holes near the Fermi level with a $\mathrm{Mn}^{3.7+}$ valence state than $\mathrm{Li}_{2} \mathrm{MnO}_{3}$, arising from the charge redistribution between the $\mathrm{O} 2 p$ and $\mathrm{Mn} 3 d$ orbitals. Importantly, the decrease in unstable $\mathrm{O} 2 p$ holes is responsible for the structural stability. On the other hand, the $E_{1 / 2}$ and limiting current density of layered $\mathrm{MnO}_{2} / \mathrm{C}$ decreased rapidly during repeated $\mathrm{CV}$ cycles, indicating the electrochemical instability of its layered structure, with its $28 \mathrm{mV}$ loss of $E_{1 / 2}$ and $13 \%$ loss in the limiting current density after 10,000 cycles. Indeed, it was proposed that the reduction of $\mathrm{O}_{2}$ initiates with the reduction of $\mathrm{Mn}^{4+}$ to $\mathrm{Mn}^{3+}\left(\mathrm{Mn}^{4+}(\mathrm{s})+\mathrm{e}^{-} \rightarrow \mathrm{Mn}^{3+}(\mathrm{s})\right)$, followed by the oxidation of $\mathrm{Mn}^{3+}\left(\mathrm{Mn}^{3+}(\mathrm{s})+\mathrm{O}_{2}\right.$ (ads) $\rightarrow \mathrm{Mn}^{4+}(\mathrm{s})$ $+\mathrm{O}_{2}{ }^{-}$(ads) $)^{49-52}$. Unfortunately, $\mathrm{Mn}^{3+}$ in the octahedral environment is unstable due to its high-energy unpaired single electron, resulting in self-stabilization that might be caused by three reaction mechanisms, namely, Jahn-Teller distortion, ORR, and disproportionation reaction 49 . Previous studies have confirmed that the incorporation of $\mathrm{Li}$ within the TM layer allows the strengthening of the TM-O bonds as a result of compensation for the loss of the $\mathrm{O}$ effective coordination number ${ }^{53}$. The increased TM-O bond strength compared to Mn-O leads to the suppression of the disproportionation reaction of $\mathrm{Mn}^{3+}$ to $\mathrm{Mn}^{4+}$ and $\mathrm{Mn}^{2+}$. To confirm this, ICP-OES was utilized to further 
characterize metal dissolution in both $\mathrm{N}_{2}$-sat. and $\mathrm{O}_{2}$-sat. electrolytes after the stability test, as shown in Fig. 4b. In $\mathrm{N}_{2}$-sat. electrolyte, HLM/C and layered $\mathrm{MnO}_{2} / \mathrm{C}$ exhibit a similar negligible dissolution of $\mathrm{Mn}(\sim 0.09 \%$ and $\sim 0.11 \%$ of $\mathrm{Mn}$ dissolved for $\mathrm{HLM} / \mathrm{C}$ and layered $\mathrm{MnO}_{2} / \mathrm{C}$, respectively). However, the presence of $\mathrm{O}_{2}$ in the electrolyte causes increased dissolution of manganese. For layered $\mathrm{MnO}_{2} / \mathrm{C}, \sim 3.9 \%$ of $\mathrm{Mn}$ was dissolved after 10,000 cycles in the $\mathrm{O}_{2}$-sat. electrolyte. In contrast, the dissolution of the corresponding Mn in HLM/C was only $~ 0.55 \%$. It is generally accepted that inducing Li within the TM layer plays an important role in stabilizing the structure ${ }^{54}$. The mixing of low valent $\mathrm{Li}^{+}$and high valent $\mathrm{Mn}^{4+}$ can effectively immobilize adjacent oxygen layers, thereby further improving electrochemical stability. Maintaining the lithium ions in octahedral sites within the TM layer is the key factor for stabilizing the layered structure over the electrocatalytic reaction process.

The morphology of HLM remained basically unchanged, as shown in Fig. 4c. The SAED pattern showed that the structure of HLM was sustained over 10,000 potential cycles (Fig. 4d). This result was further confirmed by the interplanar spacing of 0.46 $\mathrm{nm}$ and $0.23 \mathrm{~nm}$ for the (001) and (130) planes of HLM after 10,000 cycles of testing (Fig. $4 \mathrm{e}, \mathrm{f}$ ), which were similar to those of the as-prepared HLM before stability measurement. All these results demonstrated that $\mathrm{HLM} / \mathrm{C}$ is stable over a long-term electrocatalytic reaction process. Compared to other reported electrocatalysts, HLM/C shows a high stability (Supplementary Table 3).

\section{Discussion}

Theoretical description of electronic structures and mechanistic insights. To better understand the origin of the excellent ORR activity and stability, configuration interaction (CI) clustering and density functional theory (DFT) calculations were performed. In the CI calculations, the ground-state wave function of the late $3 d$ transition metal oxides (TM) is usually described as $\Phi_{\mathrm{g}}=\alpha\left|3 d^{\mathrm{n}}\right\rangle+\beta\left|3 d^{\mathrm{n}+1} \underline{L}\right\rangle+\gamma\left|3 d^{\mathrm{n}+2} \underline{L}^{2}\right\rangle^{55,56}$, where $\underline{L}$ denotes an oxygen $2 p$ hole, and $\alpha, \beta$, and $\gamma$ are linear combination coefficients to construct an orthonormal wave function $\Phi_{\mathrm{g}}$. The content of $\mathrm{O} 2 p$ holes, namely, the $\left|3 d^{\mathrm{n}+1} \underline{L}\right\rangle$ and $\left|3 d^{\mathrm{n}+2} \underline{L}^{2}\right\rangle$ configurations, increases with decreasing charge transfer energy $\Delta$. In general, $\Delta$ decreases with increasing valence of TM. In turn, the $3 d^{\mathrm{n}}$ configuration decreases from $\sim 90-95 \%$ for divalent $3 d$ elements with $\Delta \sim 7 \mathrm{eV}^{55,57}$ to only $10 \%$ for $\mathrm{Co}^{4+}$ with $\Delta \sim-4$ $\mathrm{eV}^{41}, 56$. Note that $\Delta$ decreases slightly with increasing atomic number for the later $3 d$ transition metals from $\mathrm{Mn}$ to $\mathrm{Ni}$ through $\mathrm{Fe}$ and Co.

Therefore, the $\mathrm{O} 2 p$ holes in the charge transfer insulators mainly originate from TM $3 d$ and $\mathrm{O} 2 p$ covalence $(\mathrm{O}-\mathrm{O}$ bonding), and $\Delta$ is a crucial value for the redox activity and structure stability. Using the configuration interaction cluster model, the experimental $\mathrm{Mn}-L_{2,3}$ XAS spectrum of $\mathrm{Li}_{2} \mathrm{MnO}_{3}$ (black line) and $\mathrm{LaMnO}_{3}$ (blue line) can be nicely reproduced (dashed lines below experimental data in Fig. 2a). The parameters values are $10 \mathrm{Dq}=2.0 \mathrm{eV}$ and $\Delta=-1.0 \mathrm{eV}$ for $\mathrm{Mn}^{4+}$ and $10 \mathrm{Dq}=1.0 \mathrm{eV}$, Ds $=0.21 \mathrm{eV}, \mathrm{Dt}=0.03 \mathrm{eV}$, and $\Delta=4.0 \mathrm{eV}$ for $\mathrm{Mn}^{3+17}$.

The $\mathrm{Mn} 3 d$ to $\mathrm{O} 2 p$ transfer integrals were calculated via Harrison's prescription on the basis of the Mn-O bond lengths, and the interatomic multiplet interaction (the Slater integrals) was reduced to $75 \%$ of the atomic values. The theory yields only approximately $20 \% 3 d^{3}$ for $\mathrm{Mn}^{4+}$ ions ${ }^{17}$, which means that the dominant configuration for the $\mathrm{Mn}^{4+}$ state in the ground state is $3 d^{4} L$. However, the degree of covalence is smaller than that of $\mathrm{Co}^{4+}$, which has only $8 \% 3 d^{5}$ configuration in the ground state ${ }^{41,56}$. For the $\mathrm{Mn}^{3+}$ ion, our CI theory gives $\sim 60 \% 3 d^{4}$ and a small amount of $3 d^{5} L$ configuration, namely, much fewer $\mathrm{O} 2 p$ holes. As a next step, the experimental $\mathrm{Mn}-L_{2,3}$ XAS spectrum (red line) of HLM was reproduced by $30 \% \mathrm{Mn}^{3+}$ and $70 \% \mathrm{Mn}^{4+}$ (dashed olive line below the experimental data in Fig. 2a).

The partial high oxidation state gives rise to high electrochemical performance ${ }^{40}$. Further oxidation of the lattice oxygen leads to the formation of O-O bonds, which was directly observed in the RIXS and XAS spectra at the O-K edge for the stable O $2 p$ holes $^{58}$. However, the excessive number of $\mathrm{O} 2 p$ holes in the high oxidation state is disadvantageous to the structural stability since unstable $\mathrm{O} 2 p$ holes lead to $\mathrm{O}_{2}$ release under electrochemical conditions ${ }^{17}, 59-62$. Oxygen release is well known to occur in $\mathrm{Co}^{4+}$ oxide $\mathrm{ACoO}_{3}(\mathrm{~A}=\mathrm{Ca}$ and $\mathrm{Sr})$ due to unstable $\mathrm{O} 2 p$ holes. The stable material is $\mathrm{SrCoO}_{2.7}$, possessing $\mathrm{Co}^{3.4+18-20}$. Considering that the total $\mathrm{O} 2 p$ holes in $\mathrm{Mn}^{4+}$ oxides are only half of those in $\mathrm{Co}^{4+}$ oxides, the stable valence state of the $\mathrm{Mn}$ ion could be in the range of $3.7+$ and $3.8+$, which is consistent with our experimental results in the HLM sample. Here, our results are consistent with previous findings indicating that the stability of the crystal structure increases from the $\mathrm{Mn}^{4+}$ state in $\mathrm{LiNi}_{0.5} \mathrm{Mn}_{1.5} \mathrm{O}_{4}$ to $\mathrm{Mn}^{3.67+}$ in $\mathrm{LiNi}_{0.2} \mathrm{Mn}_{1.8} \mathrm{O}_{4}{ }^{17}$. The occurrence of $\mathrm{Mn}^{3+}$ ions in the $\mathrm{Mn}^{4+}$ lattice favors its transport property through the double exchange (DE) mechanism developed by Zener ${ }^{63-65}$. In the DE scenario, electrons in a ligand $(\mathrm{O})$ between ions with different oxidation states $\left(\mathrm{Mn}^{3+}\right.$ and $\left.\mathrm{Mn}^{4+}\right)$ could easily hop (through $\mathrm{Mn}^{3+}-\mathrm{O}$ and $\mathrm{O}-\mathrm{Mn}^{4+}$ ), realizing a delocalized state with reduced kinetic energy. Hence, the transport property would be boosted, as observed in our experiments.

Although our CI calculations could naturally present the numbers of $3 d$ occupations and $\mathrm{O} 2 p$ holes within the $\mathrm{MnO}_{6}$ cluster, it was necessary to go beyond the cluster to understand transport properties. For this purpose, we turned to DFT calculations. Considering the strong correlation of the Mn-d orbitals, we adopted the DFT $+U$ method with an effective $U$ value of $4 \mathrm{eV}^{66,67}$. Note that even though the DFT $+U$ scheme is widely adopted to incorporate strong correlation, it still uses the framework of a single-electron approximation and requires comparisons with experimental observations (see Supplementary Note 2 for detailed discussions). The calculated projected density of states (PDOS) values of the $\mathrm{Li}_{2} \mathrm{MnO}_{3}$ and $\mathrm{HLM}$ models are shown in Fig. 5a-d. Overall, the band gap is reduced in the HLM system compared with that in $\mathrm{Li}_{2} \mathrm{MnO}_{3}$. Mn- $d$ and O- $p$ orbitals are the main contributors to the band gap of HLM. In the HLM system with $\mathrm{O}$ vacancies, there are two types of $\mathrm{Mn}$ ions, namely, $\mathrm{Mn}^{4+}$ and redox $\mathrm{Mn}^{3+}$, and the latter is adjacent to an $\mathrm{O}$ vacancy. From Fig. 5a, the PDOS peak positions of $\mathrm{Mn}^{4+}$ in the HLM remain similar to those in $\mathrm{Li}_{2} \mathrm{MnO}_{3}$. When the interlayer $\mathrm{Li}$ ions are fully replaced by $\mathrm{H}$, we find that these $\mathrm{H}$ atoms tend to bind to $\mathrm{O}$, leaving a channel of $\sim 2.5 \AA$ between neighboring layers, which is consistent with the refined structural data. This effect could further facilitate ion transport. In the redox HLM system, the simultaneous effects of electron hopping between $\mathrm{Mn}^{4+}$ and $\mathrm{Mn}^{3+}$ (DE mechanism) and the reduced band gap could enhance transport, which was consistent with the experimental observations.

If the transition metals are highly oxidized, excessive $\mathrm{O} 2 p$ holes exist, which are on average located at $\sim 1.1 \mathrm{eV}$ in $\mathrm{Li}_{2} \mathrm{MnO}_{3}$. In the redox HLM system, the total number of these $\mathrm{O} 2 p$ holes decreases, and their energy level increases slightly with an average value of $\sim 1.2 \mathrm{eV}$. Figure $5 \mathrm{~d}$ shows that the lowest unoccupied $\mathrm{O}$ $2 p$ state above the Fermi level in HLM is reduced with respect to that of $\mathrm{Li}_{2} \mathrm{MnO}_{3}$. This agrees well with the experimental O-K XAS spectra (Fig. 2b). We further plot the band decomposed charge density of the lowest conduction band between 0 and $2 \mathrm{eV}$ above the Fermi level before and after the replacement of $\mathrm{Li}$ by $\mathrm{H}$ (Fig. 5e). These $\mathrm{O} 2 p$ holes are relatively localized in $\mathrm{Li}_{2} \mathrm{MnO}_{3}$ and 

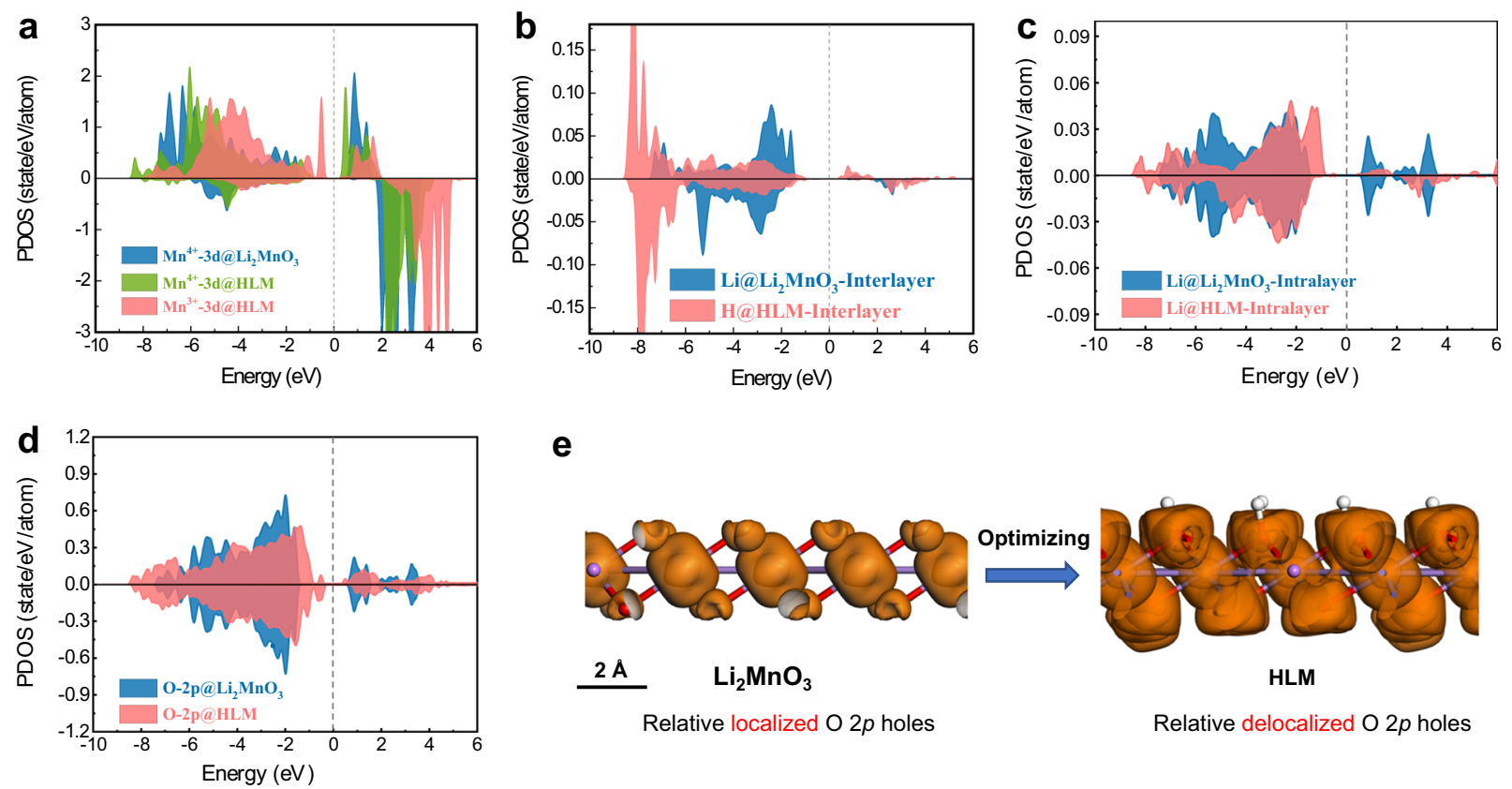

e

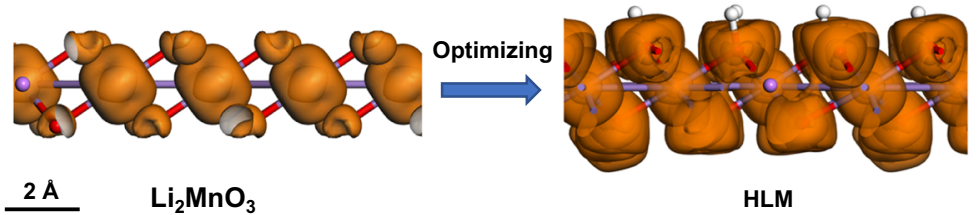

Relative localized $\mathrm{O} 2 p$ holes

Relative delocalized O $2 p$ holes
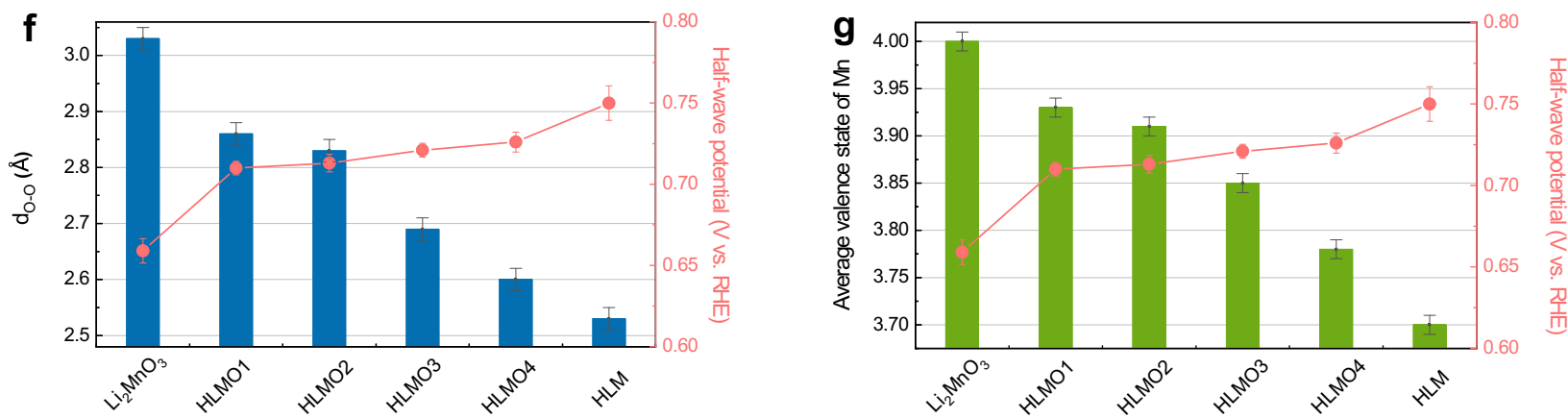

Fig. 5 Theoretical description and mechanistic study. Comparison of the PDOS of $\mathrm{Li}_{2} \mathrm{MnO}_{3}$ and $\mathrm{HLM}$ systems with a Mn-d orbitals, $\mathbf{b}$ interlayer $\mathrm{Li}-\mathrm{s}$ (in $\mathrm{Li}_{2} \mathrm{MnO}_{3}$ ) and $\mathrm{H}-\mathrm{s}$ (in HLM), c intralayer Li-s, and $\mathbf{d} \mathrm{O}-2 p$ orbitals. The energy is shifted relative to the Fermi level of HLM. e Band decomposed charge density of the lowest conduction band (between 0 and $2 \mathrm{eV}$ above the Fermi level) before and after proton exchange. Relationships of $\mathbf{f}$ interlayer distances and $\mathbf{g} \mathrm{Mn}$ valence states versus ORR activity with respect to half-wave potentials. Error bars represent the standard deviation of at least three independent measurements.

become relatively delocalized in HLM, which is consistent with the more expanded conduction band energy in the PDOS plot. By integrating these conduction band states, the total number of $\mathrm{O}$ $2 p$ holes is reduced from $\mathrm{Li}_{2} \mathrm{MnO}_{3}$ to HLM, leading to improved structural stability in the latter.

To further elucidate how the interlayer distances and the ratios of $\mathrm{Mn}^{3+} / \mathrm{Mn}^{4+}$ affect the optimization of ORR activity, we prepared control samples with different interlayer distances (Supplementary Fig. 12, Supplementary Table 4, and Supplementary Table 5) and $\mathrm{Mn}^{3+} / \mathrm{Mn}^{4+}$ ratios (Supplementary Fig. 13 and Supplementary Table 6) and further assessed their ORR performance (Supplementary Fig. 14). Indeed, the degree of protonation can be adjusted with different acid concentrations, and the ratios of $\mathrm{Li} / \mathrm{Mn}$ after acid leaching can be determined by ICP-OES. Notably, the phase transition from O3 to P3 stacking occurred as the acid concentration increased to $0.0642 \mathrm{M} \mathrm{H}_{2} \mathrm{SO}_{4}$ (HLMO3, Supplementary Fig. 12). The extracted Li number was $\sim 1.58$ (higher than the 1.5 interlayer $\mathrm{Li}$ number in $\mathrm{Li}_{2} \mathrm{MnO}_{3}$ ). This can trigger the phase transition. Figure $5 \mathrm{f}$ shows that the reduced interlayer distances yield different degrees of enhancement of ORR activity with respect to $\mathrm{E}_{1 / 2}: \mathrm{Li}_{2} \mathrm{MnO}_{3}(0.659 \mathrm{~V}$ vs. $\mathrm{RHE})<\mathrm{HLMO} 1$ (0.710 V vs. RHE) < HLMO2 (0.713 V vs. RHE)
$<$ HLMO3 $(0.721 \mathrm{~V}$ vs. RHE) < HLMO4 $(0.726 \mathrm{~V}$ vs. $\mathrm{RHE})<$ HLM ( $0.75 \mathrm{~V}$ vs. RHE). Similar trends were observed, and the ORR activity was enhanced with increasing $\mathrm{Mn}^{3+}$ ratio in the $\mathrm{Mn}^{4+}$ lattice, confirming that a favorable transport property through the DE mechanism is responsible for boosting the ORR activity, as shown in Fig. $5 \mathrm{~g}$.

Broader impact of generality and micro laminar flow fuel cell application. To further generalize the concept to a broader class of layered alkali-containing metal oxide materials, three layered alkali-containing metal oxides, namely, Na-containing $3 d$ metal oxides $\mathrm{Na}_{5 / 6} \mathrm{Li}_{1 / 4} \mathrm{Mn}_{3 / 4} \mathrm{O}_{2}$ (denoted by NLM; Fig. 6a), Licontaining $4 d$ metal oxides $\mathrm{Li}_{2} \mathrm{RuO}_{3}$ (equivalently, $\mathrm{Li}$ $\left[\mathrm{Li}_{0.33} \mathrm{Ru}_{0.67}\right] \mathrm{O}_{2}$, denoted by LRO; Fig. $6 \mathrm{~b}$ ), and Li-containing $5 d$ metal oxides $\mathrm{Li}_{2} \mathrm{IrO}_{3}$ (equivalently, $\mathrm{Li}\left[\mathrm{Li}_{0.33} \mathrm{Ir}_{0.67}\right] \mathrm{O}_{2}$, denoted by LIO; Fig. 6c), were investigated. Notably, an enhancement of the electrochemical performance was observed for layered alkalicontaining ( $\mathrm{Li}$ and $\mathrm{Na}$ ) metal (from $3 d$ to $5 d$ ) oxides upon the replacement of lithium and/or sodium with small $\mathrm{H}$, demonstrating the generality of our concept (Fig. 6d-f). The overpotential was extracted at a current density of $-3 \mathrm{~mA} \mathrm{~cm}^{-2}$ as a 

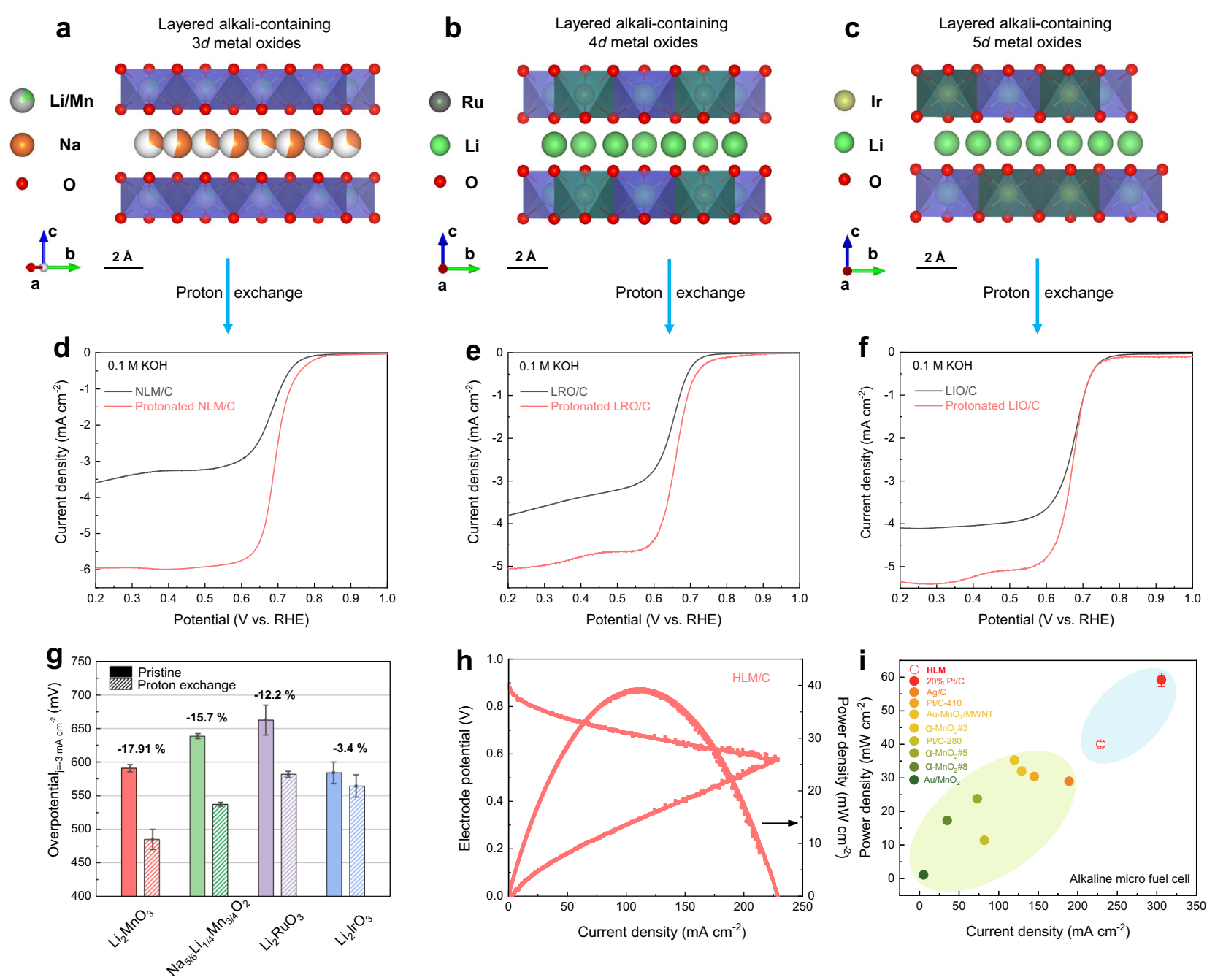

Fig. 6 Generality of concept and micro laminar flow fuel cell performance. Crystal structure configurations of a layered Na-containing $3 d$ metal oxide, b layered Li-containing $4 d$ metal oxide and $\mathbf{c l a y e r e d ~ L i - c o n t a i n i n g ~} 5 d$ metal oxide. $\mathbf{d}-\mathbf{f}$ ORR activity of layered alkali-containing ( $\mathrm{Li}$ and $\mathrm{Na}$ ) metal (from $3 d$ to $5 d$ ) oxides measured in $0.1 \mathrm{M} \mathrm{KOH}$. $\mathbf{g}$ The overpotentials of $\mathrm{Li}_{2} \mathrm{MnO}_{3}, \mathrm{Na}_{5 / 6} \mathrm{Li}_{1 / 4} \mathrm{Mn}_{3 / 4} \mathrm{O}_{2}, \mathrm{Li}_{2} \mathrm{RuO}_{3}$, and $\mathrm{Li}_{2}$ IrO $\mathrm{O}_{3}$ at a current density of $-3 \mathrm{~mA}$ cm -2 before and after proton exchange. $\mathbf{h}$ Current-potential characteristics and corresponding power density curves of $\mathrm{HLM}_{\mathrm{L}}$ in $\mathrm{H}_{2} / \mathrm{O}_{2}-\mu \mathrm{LFFC}$. $\mathbf{i}$ Comparison of the HLM with other reported catalysts in alkaline-based micro fuel cells in terms of current density and power density. Error bars represent the standard deviation of at least three independent measurements.

benchmark for the sake of comparison, as shown in Fig. 6g. Proton exchange within $\mathrm{Li}_{2} \mathrm{MnO}_{3}$ leads to an increase in electrocatalytic activity, yielding a $17.9 \%$ decrease in overpotential, whereas there is a $15.7 \%$ decrease for $\mathrm{Na}_{5 / 6} \mathrm{Li}_{1 / 4} \mathrm{Mn}_{3 / 4} \mathrm{O}_{2}$. Furthermore, a similar decreasing trend was observed for Li-rich $4 d$ and $5 d$ metal oxides, i.e., $\mathrm{Li}_{2} \mathrm{RuO}_{3}$ and $\mathrm{Li}_{2} \mathrm{IrO}_{3}$, yielding a $12.2 \%$ decrease in overpotential for $\mathrm{Li}_{2} \mathrm{RuO}_{3}$ and $3.4 \%$ for $\mathrm{Li}_{2} \mathrm{IrO}_{3}$, respectively. Proton exchange improved the ORR activity of alkali-containing metal oxide materials, providing a strategy that enables unlocking the catalytic activity.

The practical application of the as-prepared HLM catalyst in a micro laminar flow fuel cell ( $\mu$ LFFC) was demonstrated. The asprepared HLM was employed as a cathode electrocatalyst in $\mathrm{H}_{2} /$ $\mathrm{O}_{2}-\mu L F F C$. The current-potential j-E characteristics and corresponding power density curves of HLM in the $\mathrm{H}_{2} / \mathrm{O}_{2}-\mu \mathrm{LFFC}$ are shown in Fig. 6h. The open-circuit voltage of the P3-type HLM catalyst was $\sim 0.91 \mathrm{~V}$, rather close to that of $\mathrm{Pt} / \mathrm{C}(20 \mathrm{wt} \% \mathrm{Pt}$, Johnson-Matthey, $0.95 \mathrm{~V})^{68}$. In addition, excellent cell performance was obtained for the HLM with $\sim 40 \mathrm{~mW} \mathrm{~cm}^{-2}$, reaching $\sim 70 \%$ of the power density using $\mathrm{Pt} / \mathrm{C}$ in the same system (Supplementary Fig. 15). As shown in Fig. 6i, a comparison of the performance for HLM, $20 \mathrm{wt} \% \mathrm{Pt} / \mathrm{C}$, and other reported catalysts in alkaline-based micro fuel cell systems (see details in Supplementary Table 7) confirmed the superior performance of the HLM/C catalyst.

In summary, we improved the ORR activity and stability of layered manganese-based oxides through the construction of a P3-type HLM electrocatalyst by facile acid leaching on a welldefined layered O3-type $\mathrm{Li}_{2} \mathrm{MnO}_{3}$ material. The improved performance of the HLM electrocatalyst was evidenced by an improvement in the kinetic current density nearly four times higher than that of $\mathrm{Li}_{2} \mathrm{MnO}_{3}$, with almost no structural degradation over 10,000 potential cycles. The enhanced ORR performance of the HLM catalyst was related to (i) the fewer unstable $\mathrm{O} 2 p$ holes arising from the decreased manganese valence and the presence of $\mathrm{Li} / \mathrm{Mn}$ mixing in the TM layer, which can stabilize the layer structure; (ii) the interlayer distance reduction and the occurrence of $\mathrm{Mn}^{3+}$ in the $\mathrm{Mn}^{4+}$ lattice concomitant with oxygen vacancies, which can unlock a short interlayer pathway and high transport. We have shown that the optimization of both the charge state and crystalline structure boosts the catalytic activity and the stability of layered 
manganese-based oxides towards the ORR. The use of the proton exchange method for the rational design of advanced electrocatalysts can exploit a broad range of alkali-containing metal (from $3 d$ to $5 d$ ) oxide materials towards the ORR for energy conversion technology.

\section{Methods}

Materials synthesis. Rock salt monoclinic O3-type $\mathrm{Li}_{2} \mathrm{MnO}_{3}$ was prepared by a solid-state reaction. The recovered powder was further treated by acid leaching ( $2.5 \mathrm{M} \mathrm{H}_{2} \mathrm{SO}_{4}$ ) to obtain a P3-type layered HLM. There was no specific preparation procedure for the samples. For the sake of comparison, layered birnessite $\delta-\mathrm{MnO}_{2}$ was prepared. More details can be found in the Supplementary Information (Supplementary Note 1).

Physical characterization. The structure of the catalysts was characterized by $\mathrm{X}$ ray diffraction (XRD) with a Bruker D8 Advance powder diffractometer (operating at $40 \mathrm{kV}, 40 \mathrm{~mA})$ equipped with a $\mathrm{Cu}-\mathrm{K}_{\alpha}$ source $(\lambda 1=1.5405 \AA, \lambda 2=1.5443 \AA)$ and fitted with a beryllium window at room temperature. The neutron diffraction (ND) data were collected on an Echidna high-resolution neutron powder diffractometer with a wavenumber of $1.615 \AA$ at the Australian Centre for Neutron Scattering. The crystal structures were illustrated using VESTA software. Joint Rietveld refinements for XRD and ND datasets were performed with the Full-Prof program, and the refined parameters were background parameters, line shift errors (zero shift), Caglioti coefficients (U, V and W), scale factor, lattice parameters, atomic position, atomic rate occupancy and isotropic atomic displacement parameters. The procedure for the corefinements (XRD and ND) was similar to regular XRD or ND data refinement. The only difference was that the structural model was matched with both XRD and ND datasets.

The electronic structure was characterized using X-ray photoelectron spectroscopy (XPS) on a Thermo Scientific Escalab 250Xi with an Al- $\mathrm{K}_{\alpha}$ source. Soft X-ray absorption spectroscopy (XAS) experiments were performed at the $11 \mathrm{~A}$ beamline at the National Synchrotron Radiation Research Center (NSRRC) in Taiwan. Single crystals of $\mathrm{MnO}$ and $\mathrm{NiO}$ were measured simultaneously in a separate chamber as energy references for the $\mathrm{Mn}-L_{2,3}$ and $\mathrm{O}-\mathrm{K}$ edges, respectively.

The morphology of the catalysts was determined by scanning electron microscopy (SEM) on a Zeiss Supra 55 at an acceleration voltage of $5 \mathrm{kV}$. Highresolution transmission electron microscopy (HR-TEM) and selected area electron diffraction (SAED) data were collected on a JEOL $2100 \mathrm{~F}$ instrument at a working voltage of $200 \mathrm{kV}$. The $\mathrm{N}_{2}$ adsorption/desorption isotherms were recorded on a Micromeritics TriStar II 3020 at $77 \mathrm{~K}$. The stoichiometry of Li and Mn was determined, and metal dissolution in the cycled electrolyte was analyzed using inductively coupled plasma-optical emission spectrometry on an Agilent ICP-OES 730. Briefly, a dispersed catalyst suspension was drop-casted onto a polished glassy carbon disk and dried. The $0.1 \mathrm{M} \mathrm{KOH}$ electrolyte was purged with $\mathrm{N}_{2}$ or $\mathrm{O}_{2}$. After the electrolyte was $\mathrm{N}_{2}$ or $\mathrm{O}_{2}$-saturated, the drop-coated glassy carbon was used as a working electrode for long-term durability experiments over 10,000 cycles. After the durability test, the metal dissolution in the cycled electrolyte ( $\mathrm{pH}$ was adjusted to 2-4 before analyses) was analyzed using inductively coupled plasma-optical emission spectrometry.

Electrochemical characterization. For electrochemical measurements, a standard three-electrode system with a rotator (Pine Research Instrumentation, USA) was used on a Bio-Logic multichannel workstation (VMP3, Bio-Logic, France). To ensure electrical conductivity, the prepared catalysts were mixed with carbon powders (Vulcan XC-72R), and the mass ratio of carbon to catalyst was 70\%:30\%. The obtained catalysts $\left(\mathrm{HLM} / \mathrm{C}, \mathrm{Li}_{2} \mathrm{MnO}_{3} / \mathrm{C}\right.$, layered $\mathrm{MnO}_{2} / \mathrm{C}$ ) containing $3 \mathrm{mg}$ of as-prepared $\mathrm{HLM}, \mathrm{Li}_{2} \mathrm{MnO}_{3}$, layered $\mathrm{MnO}_{2}$ and $7 \mathrm{mg}$ of carbon powder (Vulcan XC-72R) were dispersed in a solution of Nafion $(0.05 \mathrm{ml}, 5 \mathrm{wt} \%$ in isopropanol, Aldrich), ethanol $(1.01 \mathrm{ml})$ and deionized (DI) water $(0.1 \mathrm{ml})$, and the resulting ink was ultrasonicated for $10 \mathrm{~min}$. The evenly dispersed catalyst ink was applied to the surface of a prepolished glassy carbon disk and dried at room temperature to form a catalyst film. The mass loading of the obtained catalytic Mn-based samples was $\sim 0.12 \mathrm{mg} \mathrm{cm}^{-2}$. For comparison, $20 \mathrm{wt} \% \mathrm{Pt} / \mathrm{C}$ (Johnson-Matthey) was purchased and studied. The three-electrode cell system used $\mathrm{Hg} / \mathrm{HgO}$ as the reference electrode, graphite as the counter electrode, and the rotating (ring-)disk electrode as the working electrode (GC electrode, $5.61 \mathrm{~mm}$ in diameter). A solution of $0.1 \mathrm{M}$ $\mathrm{KOH}$ was used as alkaline medium. The reference electrode was transferred to the reversible hydrogen electrode (RHE) using $\mathrm{E}(\mathrm{vs} . \mathrm{RHE})=\mathrm{E}(\mathrm{vs} . \mathrm{Hg} / \mathrm{HgO})+$ $0.0591 \mathrm{pH}+0.098 \mathrm{~V}$. The electrochemical data were iR-compensated. Before the collection of electrochemical data, cyclic voltammetry (CV) was performed to clean the catalyst at a scan rate of $100 \mathrm{mV} \mathrm{s}^{-1}$ for 50 cycles. Subsequently, CV was tested at a rate of $20 \mathrm{mV} \mathrm{s}^{-1}$ in the potential range between $1.2 \mathrm{~V}$ and $0.05 \mathrm{~V}$ vs. RHE. Linear sweep voltammetry (LSV) was conducted at a sweep rate of $5 \mathrm{mV} \mathrm{s}^{-1}$. The background current was corrected by subtracting the current in the $\mathrm{N}_{2}$-sat. electrolyte from that in the $\mathrm{O}_{2}$-sat. electrolyte. To determine the catalyst stability, potential cycling was performed between 0.6 and $1.0 \mathrm{~V}$ vs. RHE at $100 \mathrm{mV} \mathrm{s}^{-1}$ in both $\mathrm{O}_{2}$-sat. and $\mathrm{N}_{2}$-sat. $0.1 \mathrm{M} \mathrm{KOH}$ electrolyte.
The electron transfer number $(n)$ during the ORR was calculated by the Koutecky-Levich (K-L) equations: 69

$$
\begin{gathered}
\frac{1}{j}=\frac{1}{j_{\mathrm{L}}}+\frac{1}{j_{\mathrm{K}}}=\frac{1}{B \omega^{\frac{1}{2}}}+\frac{1}{j_{\mathrm{K}}} \\
B=0.2 n F C_{0} D_{0}^{\frac{2}{3}} \nu^{\frac{-1}{6}}
\end{gathered}
$$

where $j, j_{\mathrm{L}}$, and $j_{\mathrm{k}}$ correspond to the measured, diffusion-limiting, and kinetic current densities, respectively; $\omega$ is the rotation rate (rpm), is the Faraday constant $\left(96485 \mathrm{C} \mathrm{mol}^{-1}\right)$, is the bulk concentration of oxygen $\left(1.26 \times 10^{-6} \mathrm{~mol} \mathrm{~cm}^{-3}\right)$, is the diffusion coefficient of oxygen $\left(1.9 \times 10^{-5} \mathrm{~cm}^{2} \mathrm{~s}^{-1}\right)$; and is the kinetic viscosity $\left(0.01 \mathrm{~cm}^{2} \mathrm{~s}^{-1}\right)$.

The rotating ring-disk electrode (RRDE) approach was utilized to further determine the electron transfer number $(n)$ and byproduct peroxide species $(y)$. The potential for the Pt ring was set at $1.48 \mathrm{~V}$ vs. RHE. The calculations were made with the following formula: ${ }^{70}$

$$
\begin{aligned}
& n=4 N I_{\mathrm{D}} /\left(N I_{\mathrm{D}}+I_{\mathrm{R}}\right) \\
& y=200 I_{\mathrm{R}} /\left(N I_{\mathrm{D}}+I_{\mathrm{R}}\right)
\end{aligned}
$$

where $I_{\mathrm{D}}$ and $I_{\mathrm{R}}$ are the disk current and ring current, respectively. $N=0.37$ is the RRDE collection efficiency.

Computational methods. We performed density functional theory calculations with generalized gradient approximation (GGA) treatment of the exchange correlation functional in the Perdew-Burke-Enzerhof (PBE) form, as implemented in the Vienna ab initio simulation package (VASP) ${ }^{71-73}$. The projector augmented wave method and planewave basis set were adopted to treat the core and valence electrons, respectively. To correct for the strong correlation of magnetic Mn- $d$ orbitals, we adopted the DFT $+U$ method with an effective $U$ value of $4 \mathrm{eV}^{66,67}$ The cutoff energy for the planewave basis set was set to $500 \mathrm{eV}$. In our model, we used a simulation supercell containing $4 \mathrm{Mn}, 12 \mathrm{O}$, and $8 \mathrm{Li}$ atoms for $\mathrm{Li}_{2} \mathrm{MnO}_{3}$. For HLM, a larger supercell with $12 \mathrm{Mn}, 21 \mathrm{H}, 3 \mathrm{Li}$, and $34 \mathrm{O}$ was used to incorporate $\sim 5.5 \% \mathrm{O}$ vacancies, consistent with the refined chemical composition. Various $U$ values for $\mathrm{O} 2 p$ orbitals (when $\mathrm{O}$ vacancies were presented) were also tested, and marginal differences were obtained when $U$ was not applied (Supplementary Note 2 and Supplementary Fig. 16). Thus, in the main text, no on-site energy of $\mathrm{O} 2 p$ orbitals were used. The first Brillouin zone was represented using Monkhorst-Pack $k$-mesh with a grid density of $2 \pi \times 0.02 \AA^{-1}$. These structures were fully relaxed without any symmetry constraints until the total energy and force converged within $10^{-6} \mathrm{eV}$ and $0.01 \mathrm{eV} / \AA ̊$, respectively. We set the energy relative to the Fermi level of HLM, which was determined by the Fermi-Dirac distribution of electrons and holes at room temperature.

Micro laminar flow fuel cell characterization. The $\mathrm{H}_{2} / \mathrm{O}_{2}$ micro laminar flow fuel cell experiment was conducted by using HLM/C $\left(2.4 \mathrm{mg}_{\mathrm{HLM}} \mathrm{cm}^{-2}\right)$ as the cathode and $20 \mathrm{wt} \% \mathrm{Pt} / \mathrm{C}\left(0.8 \mathrm{mg}_{\mathrm{Pt}} \mathrm{cm}^{-2}\right.$, Johnson-Matthey) as the anode in an alkaline medium. Typically, a physical mixture (70 wt\%:30 wt\%) of Vulcan carbon (XC72R) and HLM was dispersed in a solution containing water, isopropanol and $5 \mathrm{wt}$ $\%$ Nafion by ultrasound for $2 \mathrm{~h}$. Each ink was nitrogen-sprayed ( 2 Bar max) on carbon paper (Toray Teflon Treated carbon paper, TGP-H-900, fuel cell store) and heat-treated at $90^{\circ} \mathrm{C}$. After spraying the suspension, the plate was removed $10 \mathrm{~min}$ later. The carbon paper was cooled to room temperature and then pressed between Teflon plates at 500 psi for $1 \mathrm{~min}$. In the $\mathrm{H}_{2} / \mathrm{O}_{2}$ micro laminar flow fuel cell $\left(\mathrm{H}_{2} /\right.$ $\mathrm{O}_{2}-\mu \mathrm{LFFC}$ ), a $3 \mathrm{M} \mathrm{KOH}$ electrolyte stream was introduced in the one-system channel from the bottom to the top at a flow rate of $9 \mathrm{~cm}^{3} \mathrm{~min}^{-1}$ using a micropump (Miniplus 3 Gilson). All measurements were performed at $25^{\circ} \mathrm{C}$ with $\mathrm{H}_{2} / \mathrm{O}_{2}$ under the same pressure of ca. 1 Bar.

\section{Data availability}

All relevant data are available from the corresponding authors on request. Source data are provided with this paper.

Received: 7 January 2021; Accepted: 28 April 2021; Published online: 25 May 2021

\section{References}

1. Debe, M. K. Electrocatalyst approaches and challenges for automotive fuel cells. Nature 486, 43-51 (2012).

2. Lefèvre, M., Proietti, E., Jaouen, F. \& Dodelet, J.-P. Iron-based catalysts with improved oxygen reduction activity in polymer electrolyte fuel cells. Science 324, 71-74 (2009). 
3. Gewirth, A. A., Varnell, J. A. \& DiAscro, A. M. Nonprecious metal catalysts for oxygen reduction in heterogeneous aqueous systems. Chem. Rev. 118, 2313-2339 (2018).

4. Chung, H. T. et al. Direct atomic-level insight into the active sites of a highperformance PGM-free ORR catalyst. Science 357, 479-484 (2017).

5. Robinson, D. M. et al. Photochemical water oxidation by crystalline polymorphs of manganese oxides: structural requirements for catalysis. J. Am. Chem. Soc. 135, 3494-3501 (2013).

6. El-Deab, M. S. \& Ohsaka, T. Manganese oxide nanoparticles electrodeposited on platinum are superior to platinum for oxygen reduction. Angew. Chem. Int. Ed. 45, 5963-5966 (2006).

7. Gorlin, Y. \& Jaramillo, T. F. A bifunctional nonprecious metal catalyst for oxygen reduction and water oxidation. J. Am. Chem. Soc. 132, 13612-13614 (2010).

8. Lambert, T. N. et al. Graphene-Ni- $-\mathrm{MnO}$ and $\mathrm{Cu}-\alpha-\mathrm{MnO}_{2}$ nanowire blends as highly active non-precious metal catalysts for the oxygen reduction reaction. Chem. Commun. 48, 7931-7933 (2012).

9. Cheng, F., Su, Y., Liang, J., Tao, Z. \& Chen, J. $\mathrm{MnO}_{2}$-based nanostructures as catalysts for electrochemical oxygen reduction in alkaline media. Chem. Mater. 22, 898-905 (2010).

10. Liu, Z., Xing, Y., Chen, C.-H., Zhao, L. \& Suib, S. L. Framework doping of indium in manganese oxide materials: synthesis, characterization, and electrocatalytic reduction of oxygen. Chem. Mater. 20, 2069-2071 (2008).

11. Xiao, W., Wang, D. \& Lou, X. W. Shape-controlled synthesis of $\mathrm{MnO}_{2}$ nanostructures with enhanced electrocatalytic activity for oxygen reduction. $J$. Phys. Chem. C 114, 1694-1700 (2010).

12. Tang, Q. et al. One step synthesis of carbon-supported $\mathrm{Ag} / \mathrm{Mn}_{\mathrm{y}} \mathrm{O}_{\mathrm{x}}$ composites for oxygen reduction reaction in alkaline media. Appl. Catal. B 104, 337-345 (2011).

13. Meng, Y. et al. Structure-property relationship of bifunctional $\mathrm{MnO}_{2}$ nanostructures: highly efficient, ultra-stable electrochemical water oxidation and oxygen reduction reaction catalysts identified in alkaline media. J. Am. Chem. Soc. 136, 11452-11464 (2014).

14. Choi, M. et al. Stable single-unit-cell nanosheets of zeolite MFI as active and long-lived catalysts. Nature 461, 246-249 (2009).

15. Wu, S. et al. Electrochemically reduced single-layer $\mathrm{MoS}_{2}$ nanosheets: Characterization, properties, and sensing applications. Small 8, 2264-2270 (2012).

16. Browne, M. P., Sofer, Z. \& Pumera, M. Layered and two dimensional metal oxides for electrochemical energy conversion. Energy Environ. Sci. 12, 41-58 (2019).

17. Liu, $\mathrm{H}$. et al. Insight into the role of metal-oxygen bond and $\mathrm{O} 2 \mathrm{p}$ hole in high-voltage cathode $\mathrm{LiNi}_{\mathrm{x}} \mathrm{Mn}_{2-\mathrm{x}} \mathrm{O}_{4}$. J. Phys. Chem. C 121, 16079-16087 (2017).

18. Grimaud, A. et al. Activating lattice oxygen redox reactions in metal oxides to catalyse oxygen evolution. Nat. Chem. 9, 457-465 (2017)

19. Mefford, J. T. et al. Water electrolysis on $\mathrm{La}_{1-\mathrm{x}} \mathrm{Sr}_{\mathrm{x}} \mathrm{CoO}_{3-\delta}$ perovskite electrocatalysts. Nat. Commun. 7, 1-11 (2016).

20. $\mathrm{Li}, \mathrm{X}$. et al. Exceptional oxygen evolution reactivities on $\mathrm{CaCoO}_{3}$ and $\mathrm{SrCoO}_{3}$. Sci. Adv. 5, eaav6262 (2019).

21. Guan, D. et al. Searching general sufficient-and-necessary conditions for ultrafast hydrogen-evolving electrocatalysis. Adv. Funct. Mater. 29, 1900704 (2019).

22. Robertson, A. D. \& Bruce, P. G. Mechanism of electrochemical activity in $\mathrm{Li}_{2} \mathrm{MnO}_{3}$. Chem. Mater. 15, 1984-1992 (2003).

23. Rana, J. et al. Structural changes in $\mathrm{Li}_{2} \mathrm{MnO}_{3}$ cathode material for Li-Ion batteries. Adv. Energy Mater. 4, 1300998 (2014).

24. Paik, Y., Grey, C. P., Johnson, C. S., Kim, J.-S. \& Thackeray, M. M. Lithium and deuterium NMR studies of acid-leached layered lithium manganese oxides. Chem. Mater. 14, 5109-5115 (2002).

25. Yang, $\mathrm{Y}$. et al. O-, $\mathrm{N}$-atoms-coordinated $\mathrm{Mn}$ cofactors within a graphene framework as bioinspired oxygen reduction reaction electrocatalysts. $A d v$. Mater. 30, 1801732 (2018).

26. Shang, H. et al. Engineering metal-organic framework derived $M n-N_{4}-C_{x} S_{y}$ atomic interface for highly efficient oxygen reduction reaction. Chem. Sci. 11, 5994-5999 (2020).

27. Armstrong, A. R. et al. Demonstrating oxygen loss and associated structural reorganization in the lithium battery cathode $\mathrm{Li}\left[\mathrm{Ni}_{0.2} \mathrm{Li}_{0.2} \mathrm{Mn}_{0.6}\right] \mathrm{O}_{2}$. J. Am. Chem. Soc. 128, 8694-8698 (2006).

28. Ngala, J. K., Alia, S., Dobley, A., Crisostomo, V. M. B. \& Suib, S. L. Characterization and electrocatalytic behavior of layered $\mathrm{Li}_{2} \mathrm{MnO}_{3}$ and its acid-treated form. Chem. Mater. 19, 229-234 (2007).

29. Cho, E. et al. Overview of the oxygen behavior in the degradation of $\mathrm{Li}_{2} \mathrm{MnO}_{3}$ cathode material. J. Phys. Chem. C 121, 21118-21127 (2017).

30. Chen, H. \& Islam, M. S. Lithium extraction mechanism in Li-rich $\mathrm{Li}_{2} \mathrm{MnO}_{3}$ involving oxygen hole formation and dimerization. Chem. Mater. 28, 6656-6663 (2016).
31. Xiao, R., Li, H. \& Chen, L. Density functional investigation on $\mathrm{Li}_{2} \mathrm{MnO}_{3}$. Chem. Mater. 24, 4242-4251 (2012).

32. Mitra, C. et al. Direct observation of electron doping in $\mathrm{La}_{0.7} \mathrm{Ce}_{0.3} \mathrm{MnO}_{3}$ using X-ray absorption spectroscopy. Phys. Rev. B 67, 092404 (2003).

33. Pellegrin, E. et al. Soft X-ray magnetic circular dichroism study of the colossal magnetoresistance compound $\mathrm{La}_{1-\mathrm{x}} \mathrm{Sr}_{\mathrm{x}} \mathrm{MnO}_{3}$. J. Electron. Spectrosc. Relat. Phenom. 86, 115-118 (1997).

34. Hollmann, N. et al. Local symmetry and magnetic anisotropy in multiferroic $\mathrm{MnWO}_{4}$ and antiferromagnetic $\mathrm{CoWO}_{4}$ studied by soft X-ray absorption spectroscopy. Phys. Rev. B 82, 184429 (2010).

35. Burnus, T. et al. Local electronic structure and magnetic properties of $\mathrm{LaMn}_{0.5} \mathrm{Co}_{0.5} \mathrm{O}_{3}$ studied by $\mathrm{x}$-ray absorption and magnetic circular dichroism spectroscopy. Phys. Rev. B 77, 125124 (2008).

36. De Groot, F. Multiplet effects in X-ray spectroscopy. Coord. Chem. Rev. 249, 31-63 (2005).

37. Stavitski, E. \& De Groot, F. M. F. The CTM4XAS program for EELS and XAS spectral shape analysis of transition metal L edges. Micron 41, 687-694 (2010).

38. Nemrava, S. et al. Three oxidation states of manganese in the barium hexaferrite $\mathrm{BaFe}_{12-\mathrm{x}} \mathrm{Mn}_{\mathrm{x}} \mathrm{O}_{19}$. Inorg. Chem. 56, 3861-3866 (2017)

39. Chang, C. F. et al. Spin blockade, orbital occupation, and charge ordering in $\mathrm{La}_{1.5} \mathrm{Sr}_{0.5} \mathrm{CoO}_{4}$. Phys. Rev. Lett. 102, 116401 (2009).

40. Zhou, J. et al. Voltage-and time-dependent valence state transition in cobalt oxide catalysts during the oxygen evolution reaction. Nat. Commun. 11, 1984 (2020).

41. Chin, Y. Y. et al. Spin-orbit coupling and crystal-field distortions for a lowspin $3 d^{5}$ state in $\mathrm{BaCoO}_{3}$. Phys. Rev. B 100, 205139 (2019).

42. Liu, L. et al. Probing the crystal plane effect of $\mathrm{Co}_{3} \mathrm{O}_{4}$ for enhanced electrocatalytic performance toward efficient overall water splitting. ACS Appl. Mater. Interfaces 9, 27736-27744 (2017)

43. Rong, $\mathrm{X}$. et al. Structure-induced reversible anionic redox activity in $\mathrm{Na}$ layered oxide cathode. Joule 2, 125-140 (2018).

44. Li, J. et al. Atomically dispersed manganese catalysts for oxygen reduction in proton-exchange membrane fuel cells. Nat. Catal. 1, 935-945 (2018).

45. Cheng, F. et al. Enhancing electrocatalytic oxygen reduction on $\mathrm{MnO}_{2}$ with vacancies. Angew. Chem. Int. Ed. 52, 2474-2477 (2013)

46. Wang, Z., Long, X. \& Yang, S. Effects of metal combinations on the electrocatalytic properties of transition-metal-based layered double hydroxides for water oxidation: a perspective with insights. ACS Omega 3, 16529-16541 (2018).

47. Suen, N.-T. et al. Electrocatalysis for the oxygen evolution reaction: recent development and future perspectives. Chem. Soc. Rev. 46, 337-365 (2017).

48. Zhou, Y. et al. Revealing the dominant chemistry for oxygen reduction reaction on small oxide nanoparticles. ACS Catal. 8, 673-677 (2017).

49. Lee, $\mathrm{S}$. et al. Enhanced intrinsic catalytic activity of $\lambda-\mathrm{MnO}_{2}$ by electrochemical tuning and oxygen vacancy generation. Angew. Chem. Int. Ed. 55, 8599-8604 (2016).

50. Roche, I., Chaînet, E., Chatenet, M. \& Vondrák, J. Carbon-supported manganese oxide nanoparticles as electrocatalysts for the oxygen reduction reaction (ORR) in alkaline medium: physical characterizations and ORR mechanism. J. Phys. Chem. C 111, 1434-1443 (2007).

51. Cao, Y. L., Yang, H. X., Ai, X. P. \& Xiao, L. F. The mechanism of oxygen reduction on $\mathrm{MnO}_{2}$-catalyzed air cathode in alkaline solution. J. Electroanal. Chem. 557, 127-134 (2003).

52. Lima, F. H. B., Calegaro, M. L. \& Ticianelli, E. A. Electrocatalytic activity of manganese oxides prepared by thermal decomposition for oxygen reduction. Electrochim. Acta 52, 3732-3738 (2007)

53. You, Y. et al. Insights into the improved high-voltage performance of Liincorporated layered oxide cathodes for sodium-ion batteries. Chem 4 2124-2139 (2018)

54. Yang, L. et al. Lithium-doping stabilized high-performance P2- $\mathrm{Na}_{0.66} \mathrm{Li}_{0.18} \mathrm{Fe}_{0.12} \mathrm{Mn}_{0.7} \mathrm{O}_{2}$ cathode for sodium ion batteries. J. Am. Chem Soc. 141, 6680-6689 (2019).

55. Van der Laan, G., Zaanen, J., Sawatzky, G. A., Karnatak, R. \& Esteva, J.-M. Comparison of X-ray absorption with X-ray photoemission of nickel dihalides and NiO. Phys. Rev. B 33, 4253 (1986).

56. Potze, R. H., Sawatzky, G. A. \& Abbate, M. Possibility for an intermediate-spin ground state in the charge-transfer material $\mathrm{SrCoO}_{3}$. Phys. Rev. B 51, 11501 (1995).

57. Csiszar, S. I. et al. Controlling orbital moment and spin orientation in $\mathrm{CoO}$ layers by strain. Phys. Rev. Lett. 95, 187205 (2005).

58. House, R. A. et al. Superstructure control of first-cycle voltage hysteresis in oxygen-redox cathodes. Nature 577, 502-508 (2020).

59. Hausbrand, R. et al. Fundamental degradation mechanisms of layered oxide Li-ion battery cathode materials: methodology, insights and novel approaches. Mater. Sci. Eng. B 192, 3-25 (2015).

60. Sathiya, M. et al. Reversible anionic redox chemistry in high-capacity layeredoxide electrodes. Nat. Mater. 12, 827-835 (2013). 
61. Grimaud, A., Hong, W. T., Shao-Horn, Y. \& Tarascon, J.-M. Anionic redox processes for electrochemical devices. Nat. Mater. 15, 121-126 (2016).

62. Myeong, S. et al. Understanding voltage decay in lithium-excess layered cathode materials through oxygen-centred structural arrangement. Nat. Commun. 9, 1-10 (2018).

63. Zener, C. Interaction between the $d$ shells in the transition metals. Phys. Rev. 81, 440 (1951)

64. Zener, C. Interaction between the $d$-shells in the transition metals. II. Ferromagnetic compounds of manganese with perovskite structure. Phys. Rev. 82, 403 (1951).

65. Zener, C. Interaction between the $d$-shells in the transition metals. III. Calculation of the Weiss factors in Fe, Co, and Ni. Phys. Rev. 83, 299 (1951).

66. Wang, L., Maxisch, T. \& Ceder, G. Oxidation energies of transition metal oxides within the GGA $+U$ framework. Phys. Rev. B 73, 195107 (2006).

67. Kan, M., Zhou, J., Sun, Q., Kawazoe, Y. \& Jena, P. The intrinsic ferromagnetism in a $\mathrm{MnO}_{2}$ monolayer. J. Phys. Chem. Lett. 4, 3382-3386 (2013).

68. García-Rosado, I. J., Uribe-Calderon, J. \& Alonso-Vante, N. Nitrogen-doped reduced graphite oxide as a support for CoSe electrocatalyst for oxygen reduction reaction in alkaline media. J. Electrochem. Soc. 164, F658-F666 (2017).

69. Bard, A. J. \& Faulkner, L. R. Electrochemical Methods: Fundamentals and Applications (Wiley, 2001).

70. Paulus, U. A., Schmidt, T. J., Gasteiger, H. A. \& Behm, R. J. Oxygen reduction on a high-surface area $\mathrm{Pt} / \mathrm{Vulcan}$ carbon catalyst: a thin-film rotating ringdisk electrode study. J. Electroanal. Chem. 495, 134-145 (2001).

71. Perdew, J. P., Burke, K. \& Ernzerhof, M. Generalized gradient approximation made simple. Phys. Rev. Lett. 77, 3865 (1996).

72. Kresse, G. \& Joubert, D. From ultrasoft pseudopotentials to the projector augmented-wave method. Phys. Rev. B 59, 1758 (1999).

73. Kresse, G. \& Furthmüller, J. Efficient iterative schemes for $a b$ initio totalenergy calculations using a plane-wave basis set. Phys. Rev. B 54, 11169 (1996).

\section{Acknowledgements}

The work leading to these results has received funding from the National Nature Science Foundation of China (no. 21805209) and the Fundamental Research Funds for the Central Universities. We acknowledge the support from the Max Planck-POSTECH-Hsinchu Center for Complex Phase Materials and valuable discussions with Prof. L.H. Tjeng.

\section{Author contributions}

J.M. conceived and coordinated the project. X.Z., M.O., X.W., Y.Y.H., H. Zeng, S.W., L.H., H. Zhong, N.A.-V., C.-W.W., W.-B.W., H.-J.L., C.-T.C., Z.H., Y.H., and J.M. carried out experimental work and data analysis. X.W., K.L., J.Z., and Z.H. performed theoretical calculations. All authors discussed the results. X.Z., N.A.-V., Z.H., Y.H., and J.M. wrote the manuscript with the contributions of all co-authors.

\section{Competing interests}

The authors declare no competing interests.

\section{Additional information}

Supplementary information The online version contains supplementary material available at https://doi.org/10.1038/s41467-021-23430-3.

Correspondence and requests for materials should be addressed to Z.H., Y.H. or J.M.

Peer review information Nature Communications thanks the anonymous reviewers for their contributions to the peer review of this work.

Reprints and permission information is available at http://www.nature.com/reprints

Publisher's note Springer Nature remains neutral with regard to jurisdictional claims in published maps and institutional affiliations.

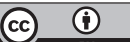

Open Access This article is licensed under a Creative Commons Attribution 4.0 International License, which permits use, sharing, adaptation, distribution and reproduction in any medium or format, as long as you give appropriate credit to the original author(s) and the source, provide a link to the Creative Commons license, and indicate if changes were made. The images or other third party material in this article are included in the article's Creative Commons license, unless indicated otherwise in a credit line to the material. If material is not included in the article's Creative Commons license and your intended use is not permitted by statutory regulation or exceeds the permitted use, you will need to obtain permission directly from the copyright holder. To view a copy of this license, visit http://creativecommons.org/ licenses/by/4.0/.

(C) The Author(s) 2021 